\title{
ECONOMIC STUDY FOR FISH PRODUCTION IN DAMIETTA GOVERNORATE
}

Hamida, S. A. M. and Y. T.A. Hamza

Agric. Economic Res. institute. Agric. Res. Center

دراسة اقتصادية لأنماط الاستزراع السمكى و أهم المشاكل التى تواجهه فى محافظة

دمياط

سمير انور متولي حميدة و ياسر توفيق احمد حمزة

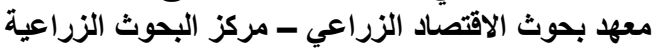

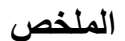

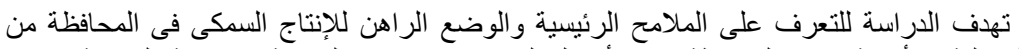

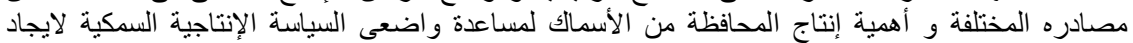

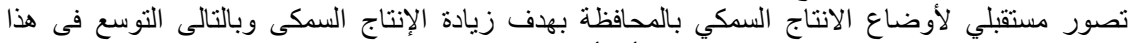

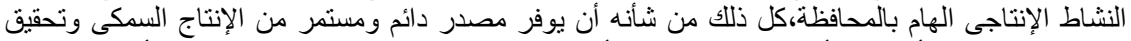

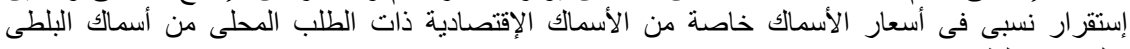

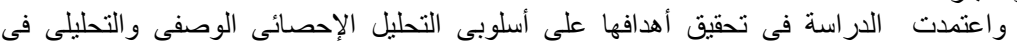
و البورى و الطبار .

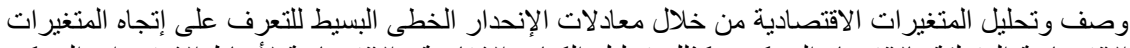

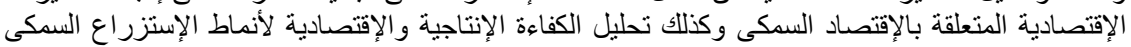

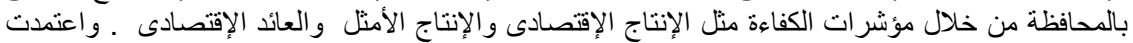

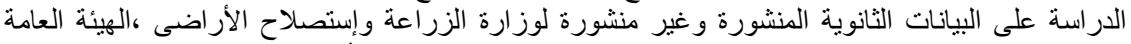

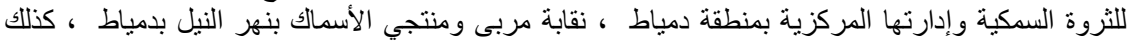

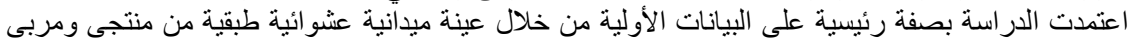

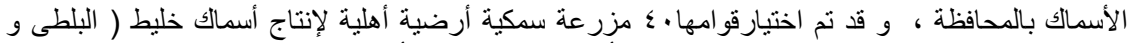

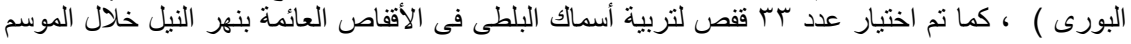

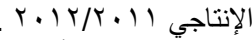

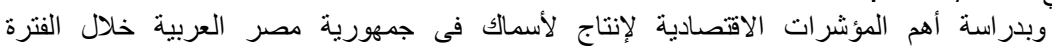

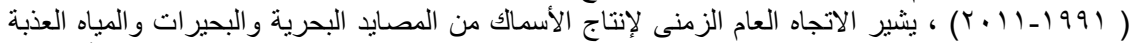

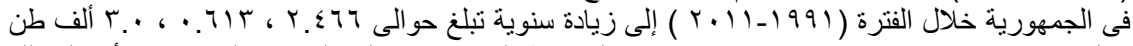

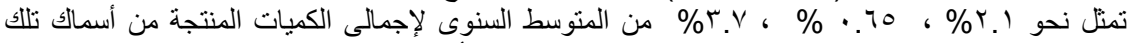

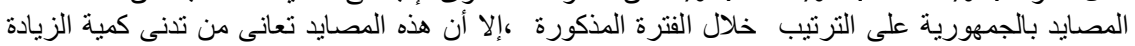

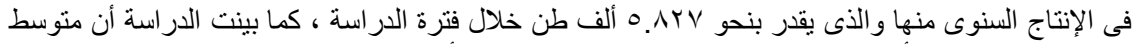

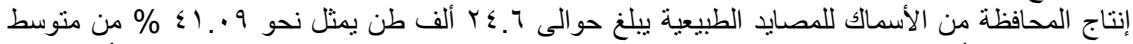

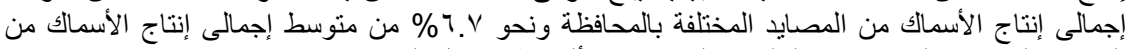

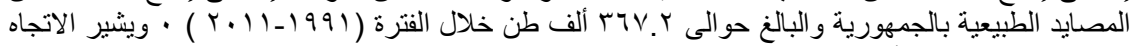

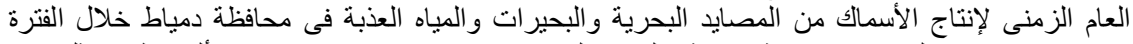

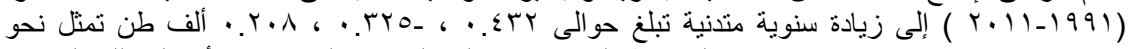

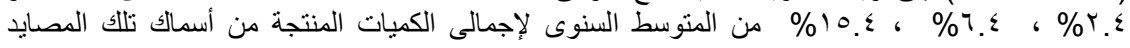

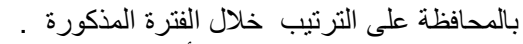

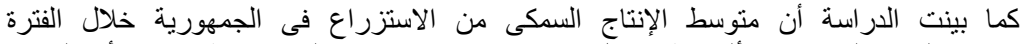

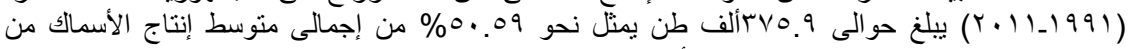

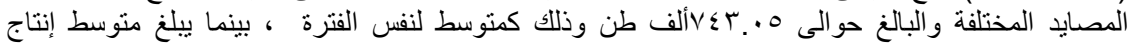

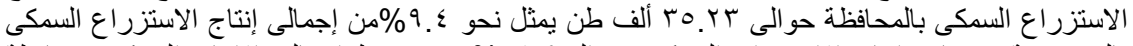

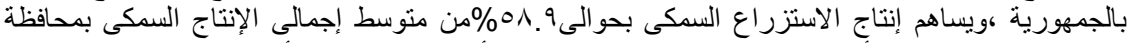

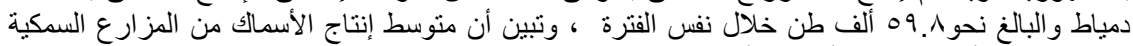

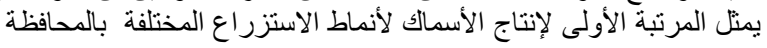




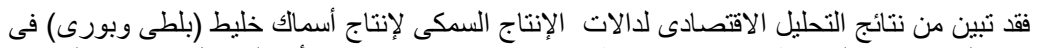

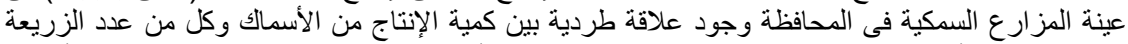

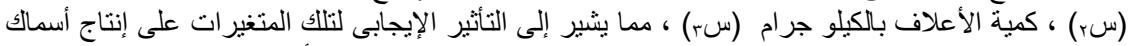

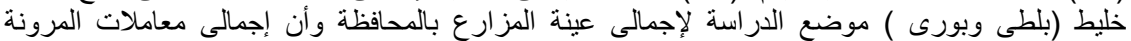

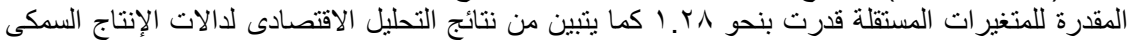

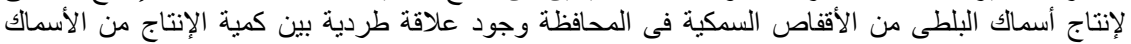

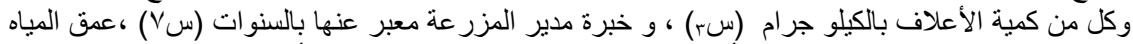

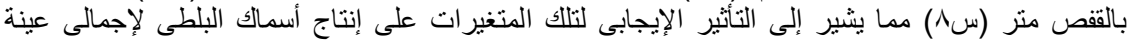

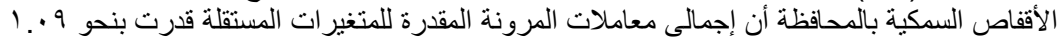

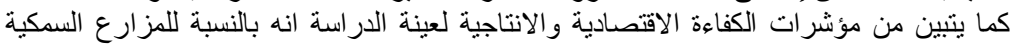

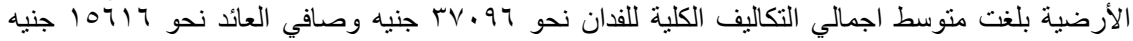

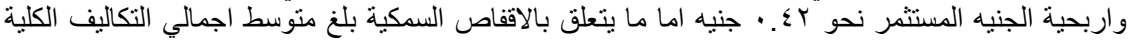

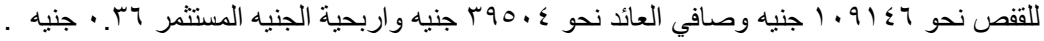

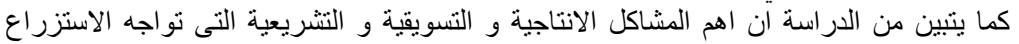

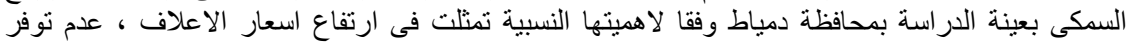

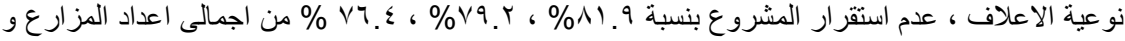

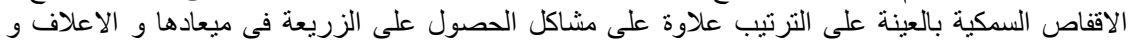

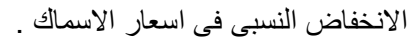

\section{المقدمة}

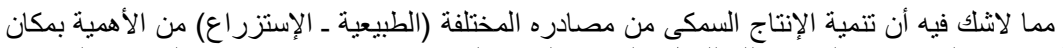

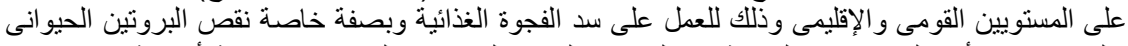

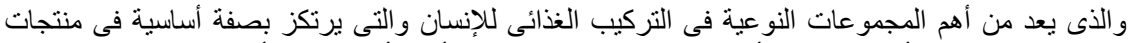

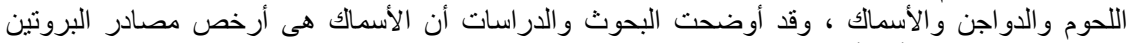

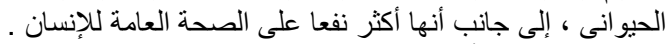

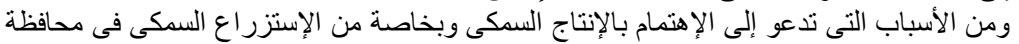

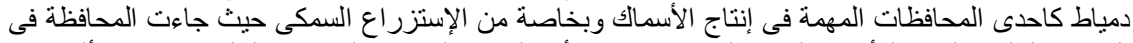

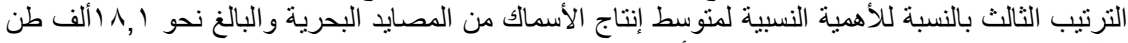

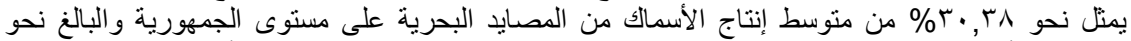

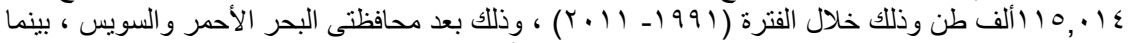

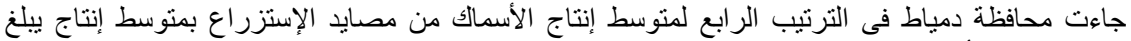

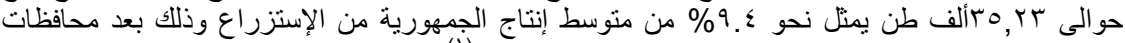

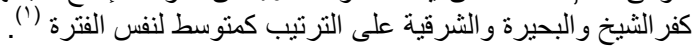

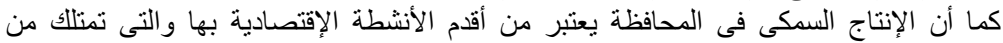

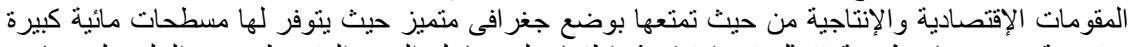

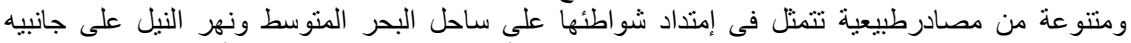

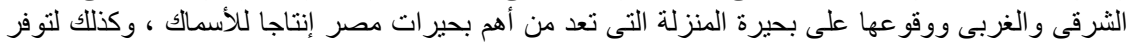

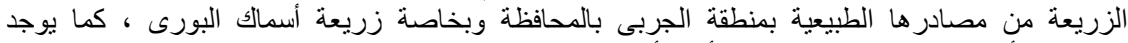

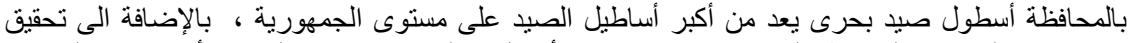

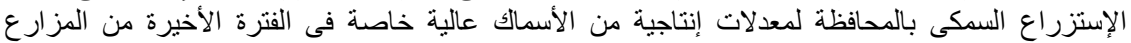

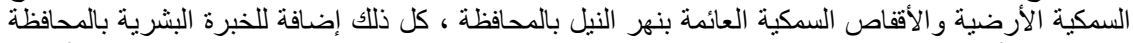
فى إنتاج الأسماك بمايمكنها للإحتفاظ بهذه المكانة المتميزة بين محافظات الجمهورية فى إنتاج الإنة الأسماك وبخاصة من الإستزر اع السمكى .

(1) جمعت وحصبت من الجدول رقم (1) بالدراسة.

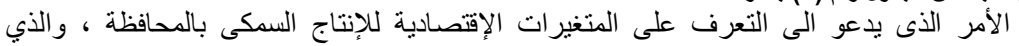

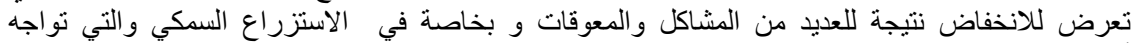
أصحاب المزارع من النواحي الإنتاجية والتسويقية والقانونية والتشريعية وكذللك نقط الضعف واعن ومعالجتها 
و التوصل اللى الحلول المناسبة لتلك المشاكل وذلك للعمل على التوسع فى هذا النشاط الإنتاجى المهم بالمحافظة

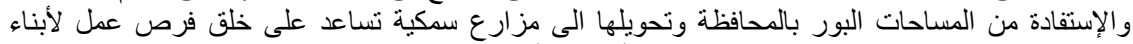

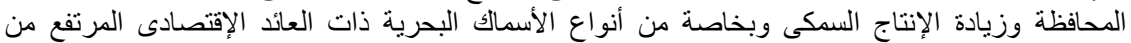

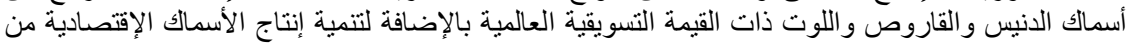

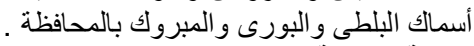

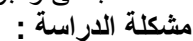

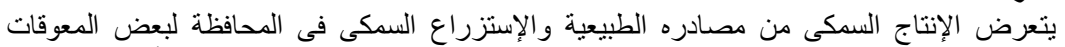

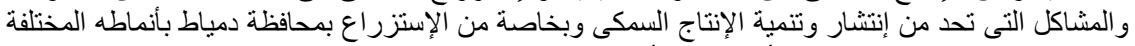

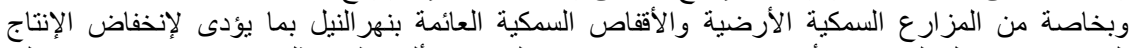

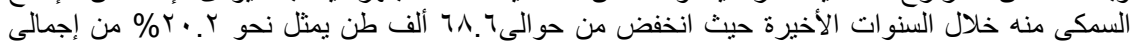

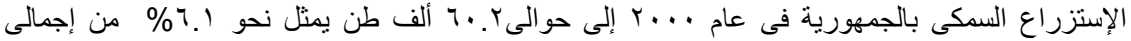

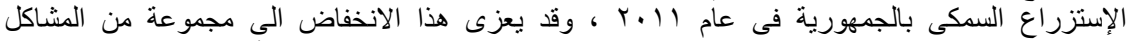

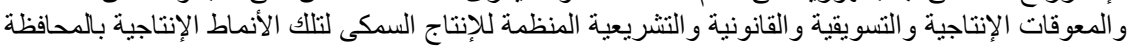

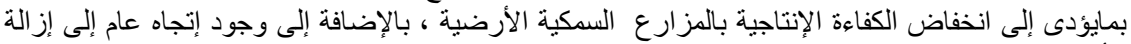

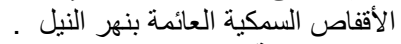
هدف الاراسة :

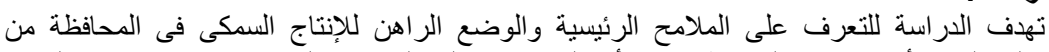

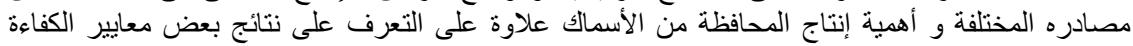

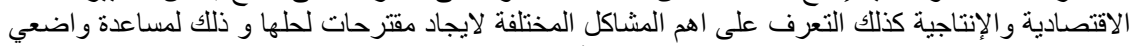

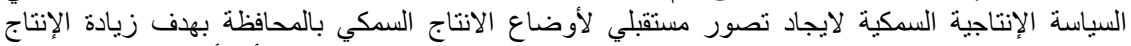

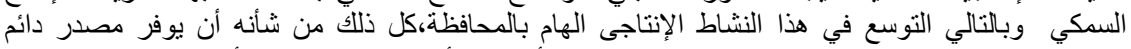

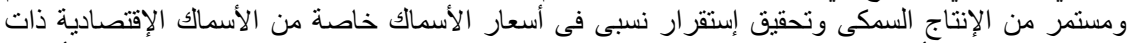

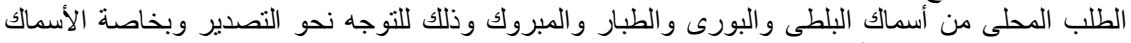

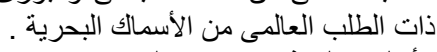

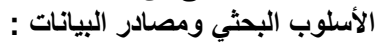

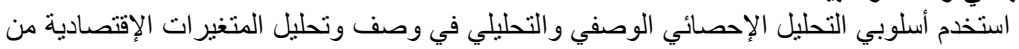

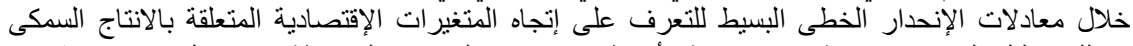

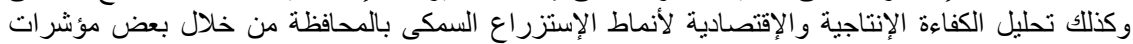

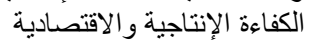

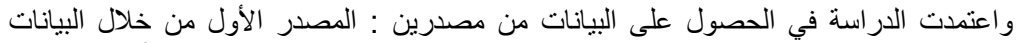

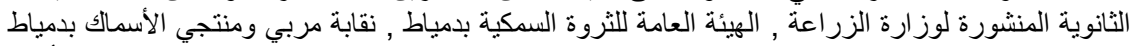

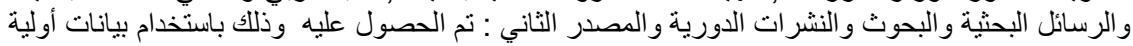

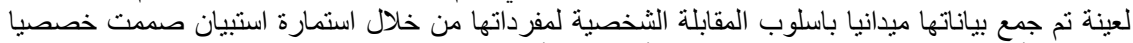

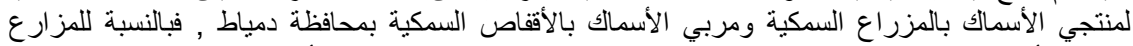

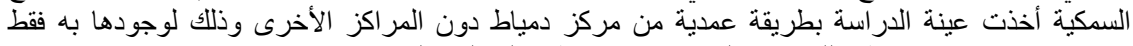

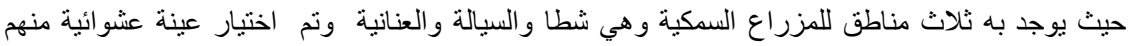

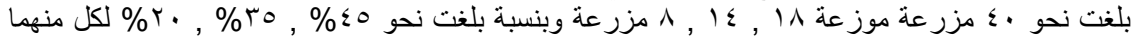

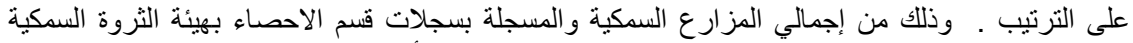

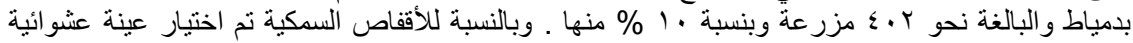

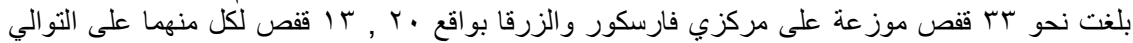

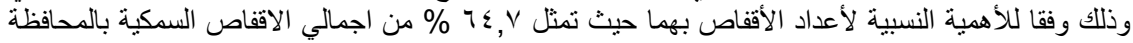

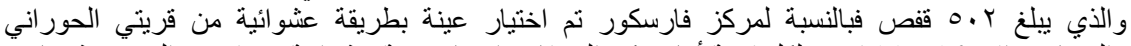

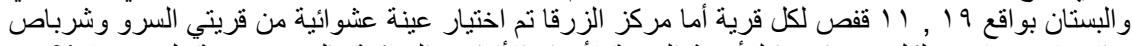

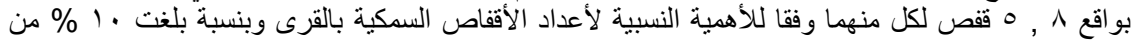

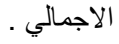


Hamida, S. A. M. and Y. T.A. Hamza

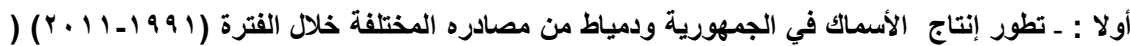

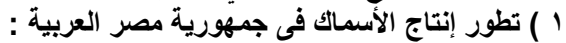

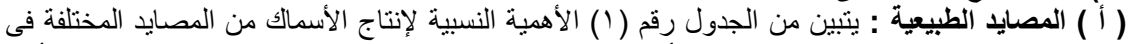

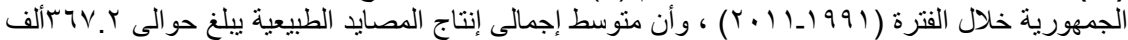

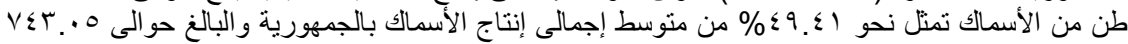

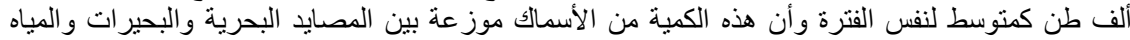

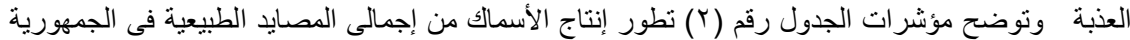

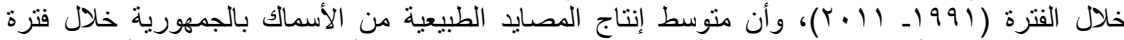

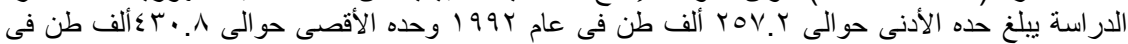

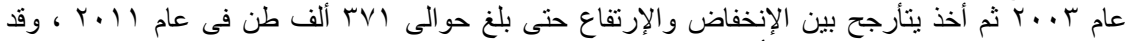

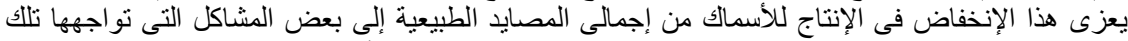

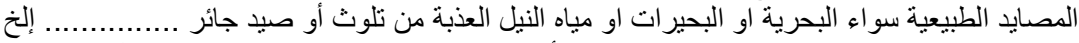

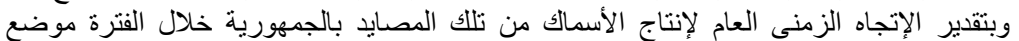

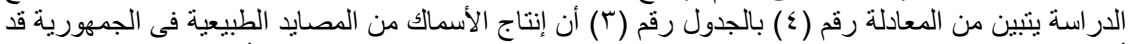

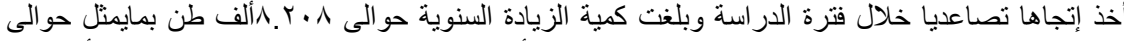

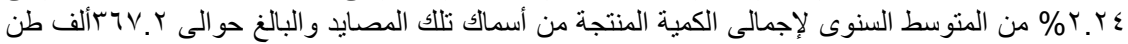

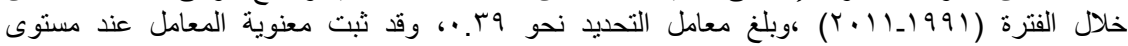

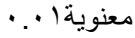

جدول رقم ( 1 ) : الأهمية النسبية للإنتاج السمكى من المصايد المختلفة فى الجمهورية وفى محافظة " دمياط ونسبة ما يساهم به إنتاج المحافظة من إجمالى الجمهورية كمتوسط للفترة

( الوحدة بالطن )

$(r+11-1991)$

\begin{tabular}{|c|c|c|c|c|c|c|c|}
\hline \multirow{2}{*}{ 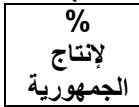 } & \multicolumn{3}{|c|}{ محافظة دمياط } & \multicolumn{3}{|c|}{ إجمالى الجمهورية } & \multirow{2}{*}{ المصايد المختلفة } \\
\hline & $\%$ & $\%$ & 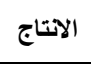 & $\%$ & $\%$ & 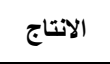 & \\
\hline 10.1 & $V T .9 T$ & $\Gamma \cdot . \Gamma$ & $1 \wedge 1 \mathrm{~V}$ & TI.T & $10 . \leqslant 1$ & $110.1 \varepsilon$ & إجمالي البحار \\
\hline Y.90 & $r . .09$ & $\wedge . \leqslant 7$ & 0.7. & $\Sigma \eta . V T$ & rT..9 & $1 V 10 \wedge 7$ & إجمالي البحير ات \\
\hline I.V & $0 . \leqslant \Lambda$ & Y.YO & $1 T \leqslant V$ & 11.90 & $1 \cdot . \wedge \leq$ & $\Lambda .0 V Y$ & المياه العذبة \\
\hline 7. . & $1 \ldots$ & $\varepsilon 1.9$ & $r \leqslant 0 V V$ & $1 \cdots$ & $\{9 . \leqslant 1$ & ruVIVY & |ـ إجمالي المصايد الطبيعية \\
\hline $9 . \varepsilon$ & & 01.91 & TOYYV & & $0 . .09$ & rVONVq & ץ - إجمالي مصايد الاستزراع \\
\hline A. 0 & & $1 \cdots$ & $091 \cdot \varepsilon$ & & $1 \cdots$ & $V \leqslant r .01$ & r ـ إجمالي المصايد المختلفة \\
\hline
\end{tabular}

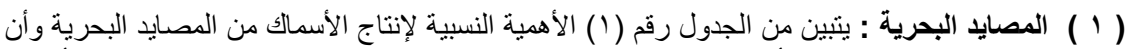

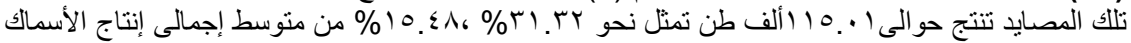

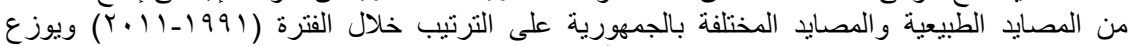

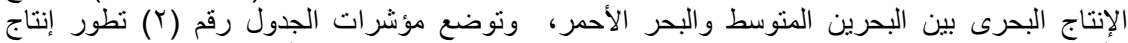

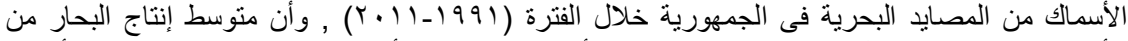

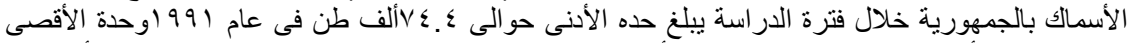

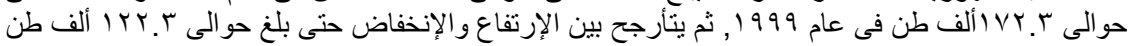

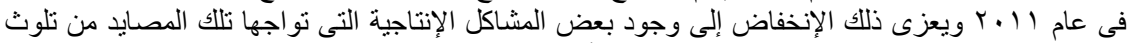

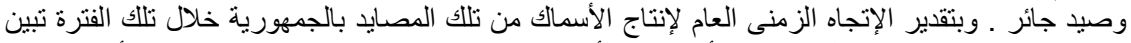

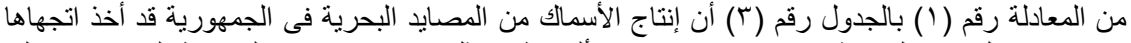

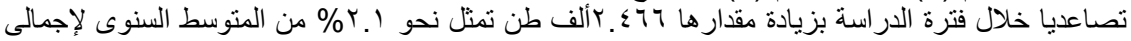

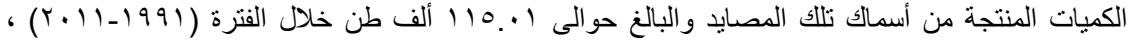

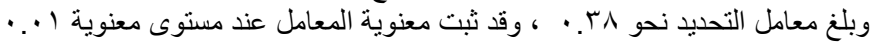


جدول رقم ( r ) تطور انتاج الأسماك من المصايد المختلفة في جمهورية مصر العربية خلال الفترة $(r+11-1991)$

\begin{tabular}{|c|c|c|c|c|c|c|}
\hline الإجمالى العام & إلاسمالى إنتاج & المصايد الطبيعية إنتاج & إنتاج المياه & إنتاج البحيرات & إنتاج البحار & السنوات \\
\hline 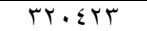 & $7 \ldots$ & $Y T \cdot \leqslant Y T$ & TVOIT & $1 \leqslant \Lambda r \leqslant 9$ & $V \leqslant 771$ & 1991 \\
\hline TIVTr. & $7 \ldots$ & TOVTT. & $M \Psi . V V$ & $1 \leqslant I V Y Y$ & 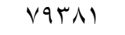 & 1994 \\
\hline rrarr. & $0 \leq \ldots$ & rVo010 & \{0rTा & $1 \leqslant r r 90$ & Кт9Y & 1994 \\
\hline rrqvAq & or... & KATVAq & OrYAO & $1 \leqslant q \cdot V r$ & $10 \leqslant \pi$ & 1998 \\
\hline$\varepsilon \cdot V \cdot r q$ & $V I V . T$ & rTort. & OVAVY & IATEAV & 9.971 & 1990 \\
\hline$\sum \leqslant 79 \wedge 7$ & 9111. & ro01. 1 & $\vee 9 \vee \leq 7$ & IVTOTV & $990 Y T$ & 1999 \\
\hline 纟79YAT & Nov. \{ & TATONT & VYVAO & $1907 \pi r$ & 11.170 & 1998 \\
\hline $007 \leqslant 9 \pi$ & 1 1 $94 \wedge 9$ & $\varepsilon|V| \cdot \varepsilon$ & V9lor & rirAM9 & $1 \% 0.74$ & 1991 \\
\hline 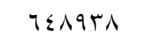 & FrTYVY & STYTTा & ד & 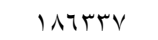 & IVTrET & 1999 \\
\hline$V Y \leq \leqslant \leq 9$ & $r \varepsilon \cdot 1 \cdot 1$ & $r \Lambda \leq r \leq 1$ & A.rYI & $|V T| \leq q$ & $M \cdot \Lambda \leq \varepsilon$ & $r \ldots$ \\
\hline$V V .197$ & $r \leqslant r \cdot T \leqslant$ & STVITY & $1.9 \wedge 1 \mathrm{~V}$ & $M \Lambda \varepsilon \cdot V Y$ & אעוזו & $r \ldots l$ \\
\hline $1.1 \leq 77$ & rVTrqT & Erolv. & Ir. Nor & |VIAI. & Iro.h & $r \ldots r$ \\
\hline Av०9 . & $\varepsilon \leqslant 0 \mid 11$ & $\varepsilon r \cdot \Lambda . q$ & וג.. & $1901 Y 1$ & |VTN| & $r \ldots r$ \\
\hline $170 . \mathrm{rq}$ & EVloro & 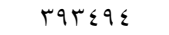 & $1.0 \ldots$ & 187.99 & 1111490 & $r \ldots \varepsilon$ \\
\hline А८q५.. & or $q v \leqslant V$ & $r \leqslant 900 r$ & $\Lambda r \Lambda . r$ & $19110 \leqslant$ & $1 \cdot v \leqslant 0 r$ & $r \ldots q$ \\
\hline qV. QYT & 090.19 & rVOAq & $1 . \leq 9 \vee 7$ & $101 \pi 1 K$ & 1197.7 & $r \ldots r$ \\
\hline $1 \ldots \wedge$ & 750017 & TVY $\{q 1$ & 9VY). & I & $M \cdot V \leqslant \Lambda$ & $r \ldots v$ \\
\hline 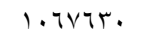 & 794110 & TVTNIO & 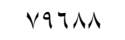 & loVA $\varepsilon \varepsilon$ & Irur & $r \ldots \Lambda$ \\
\hline $1.9 Y \wedge \wedge 1$ & $v .0 \leqslant 9$. & rNvrqA & AVTrO & WVYYSY & IYVAYI & $r \ldots q$ \\
\hline $1 \pi . \leq \vee 9 \leq$ & 919010 & rNor. 9 & $\lambda \leq T \leq \Lambda$ & $1 \vee 9199$ & rוrו & r.l. \\
\hline ITIVE & १人т人ץ. & $r V .970$ & NQVIT & 10190. & ITKT.T & $r .11$ \\
\hline$V \leqslant r .01$ & rVONVq & TIVIVY & $1.0 \mathrm{VY}$ & 171017 & $110.1 \leq$ & المتوسط \\
\hline
\end{tabular}

المصدر : وزارة الزراعة واستصلاح الأراضى ، الهيئة العامة لتنمية الثروة السمكية ، نثرة إحصاءات الإنتاج السمكى ، القاهرة ،

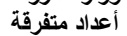

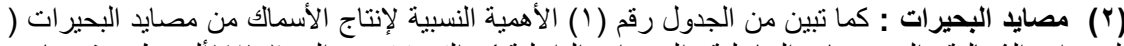

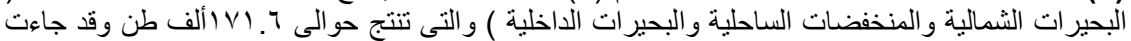

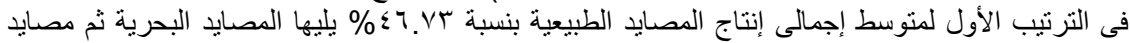

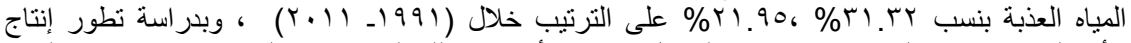

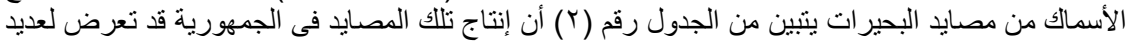

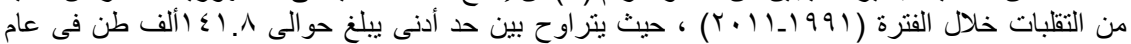

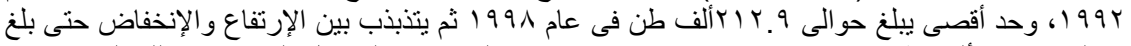

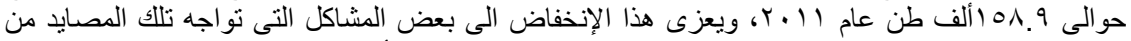

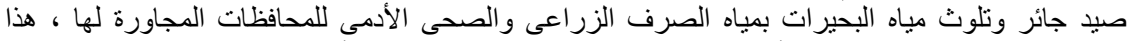

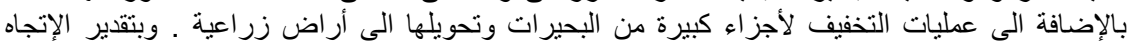

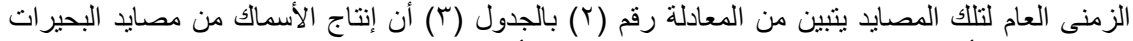

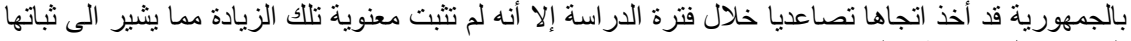

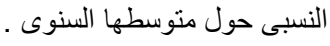

جدول رقم ( َ) : معادلات الإتجاه الزمني العام لتطور إنتاج الأسماك من المصايد المختلفة فى الجمهورية $(4.11-1991)$

$$
\text { خلال القترة }
$$

\begin{tabular}{|c|c|c|c|c|c|}
\hline المعنوية & ف & ני & المعادلـــــــــــة & | المعادئة & المصايد \\
\hline
\end{tabular}


Hamida, S. A. M. and Y. T.A. Hamza

\begin{tabular}{|c|c|c|c|c|c|}
\hline$\because \cdot 1$ & $91 . \cdot 1$ & $\cdot r \Lambda$ & 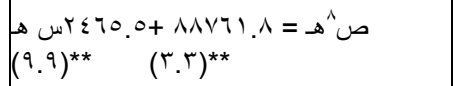 & (1) & انتاج البحار \\
\hline - & $\therefore \leqslant 9$ &.$r$ & 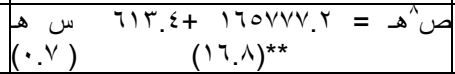 & $(Y)$ & انتاج البحير ات \\
\hline$\because \cdot 1$ & 11.10 & .0 . & 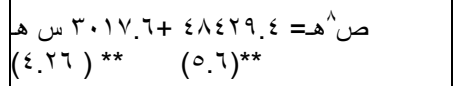 & $(r)$ & انتاج المياه العذبة \\
\hline$\because \cdot 1$ & 11.07 & $\cdot r q$ & 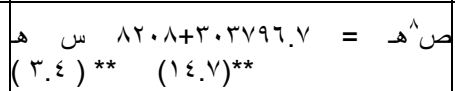 & $(\varepsilon)$ & الطيعيايد \\
\hline$\because \cdot 1$ & rAo.7l & .91 & ص هـ & $(0)$ & الاستزراع ايد \\
\hline$\because \cdot 1$ & YNo.T1 & .91 & 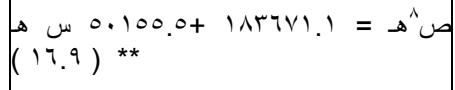 & $(7)$ & الاجمالى العام للانتاج \\
\hline
\end{tabular}

(ץ) مصايد المياه العذبة : حيث يتبين من الجدول رقم ( (1) أن متوسط إجمالى إنتاج الأسماك من مصايد

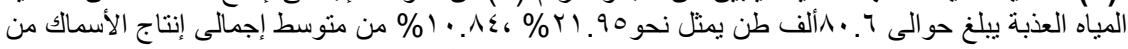

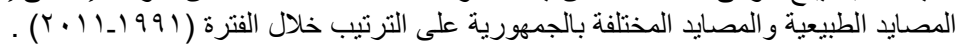

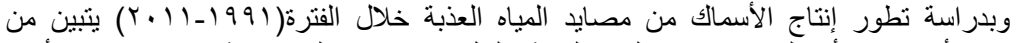

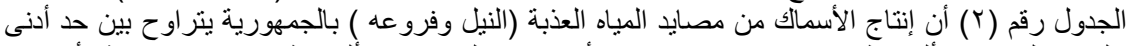

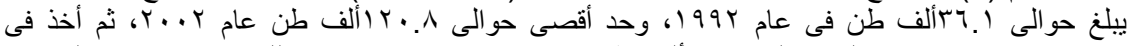

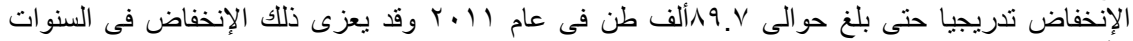

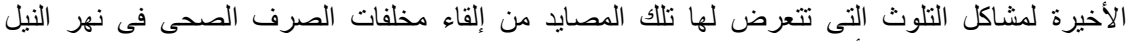

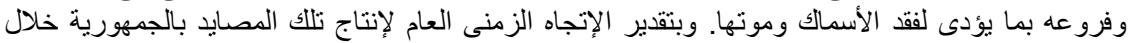

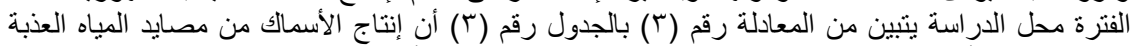

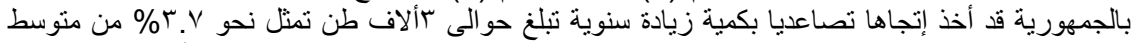

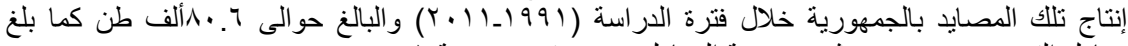

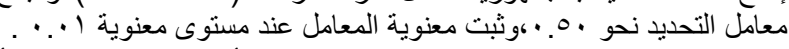

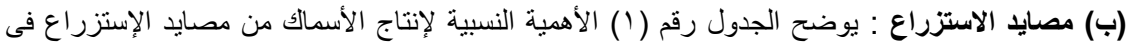

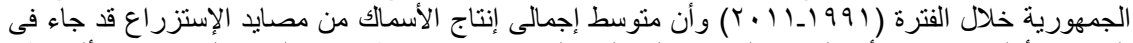

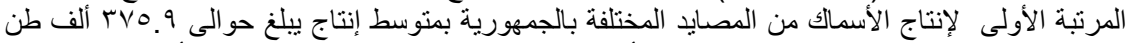

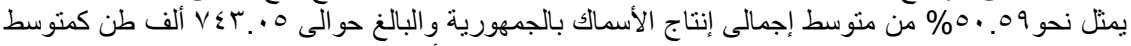

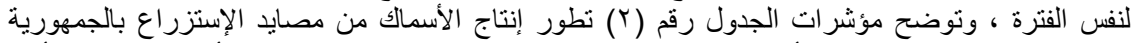

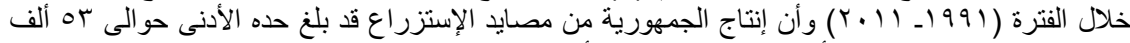

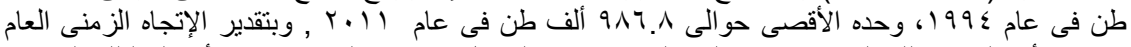

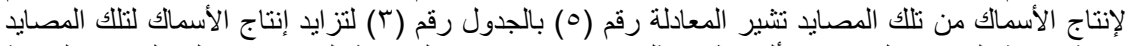

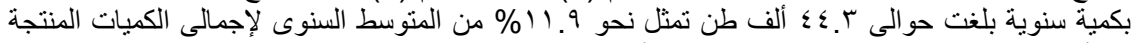

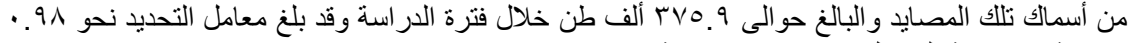

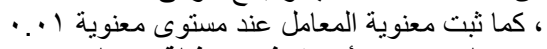

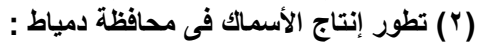
( أ) المصايد الطبيعية : يتبين من الجدول رقم ( (1) أن متوسط إنتاج المحافظة من الأسماك للمصايد الطبيعية

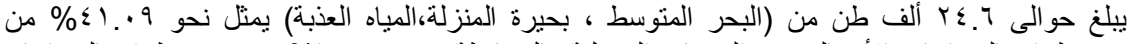

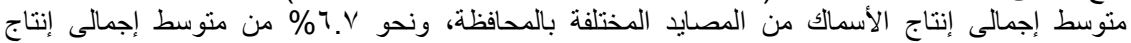

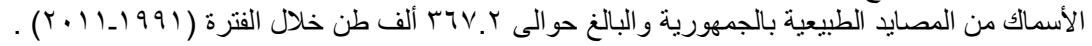




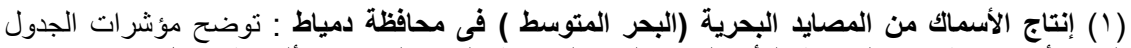

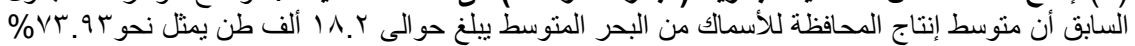

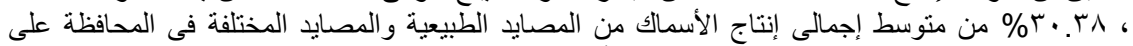

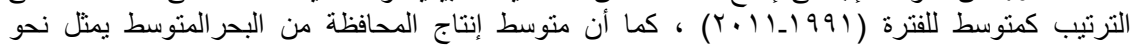

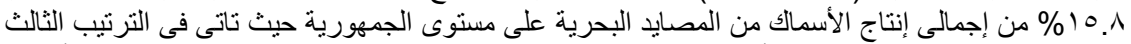

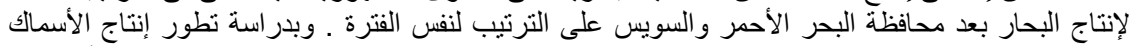

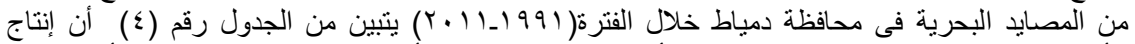

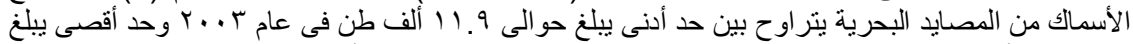

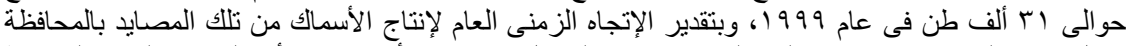

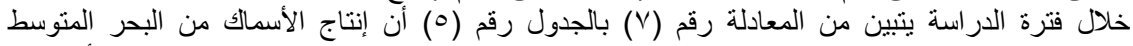

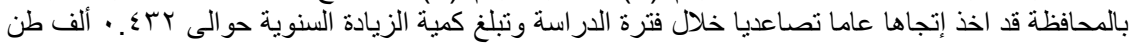

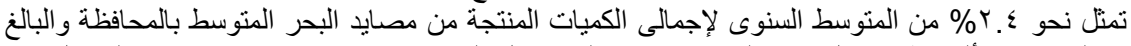

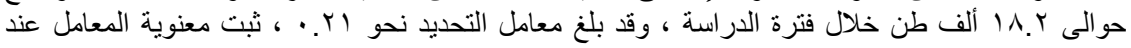

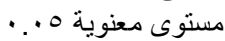

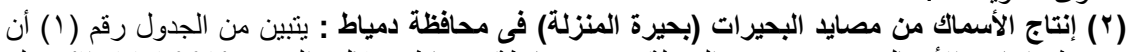

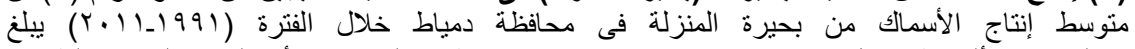

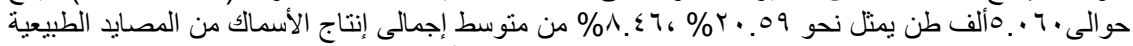

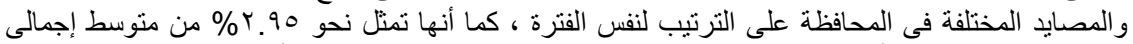

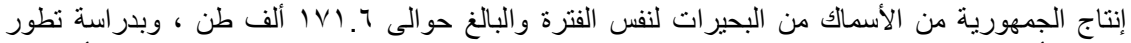

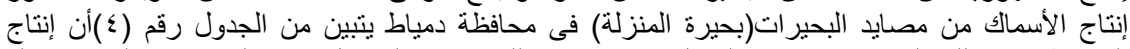

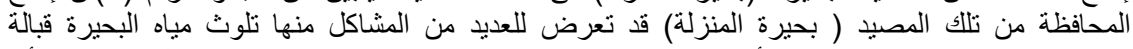

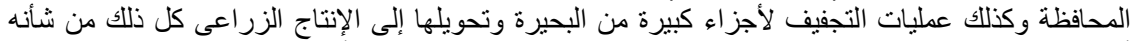

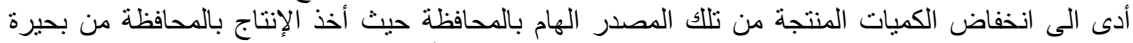

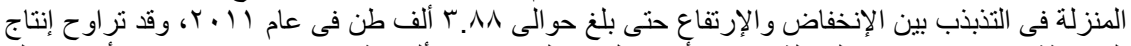

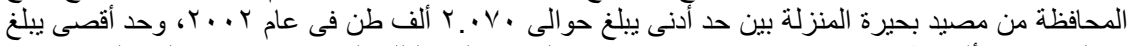

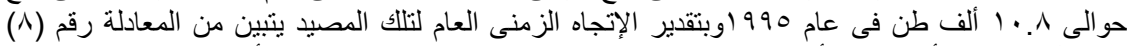

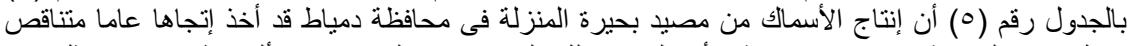

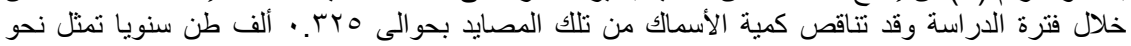

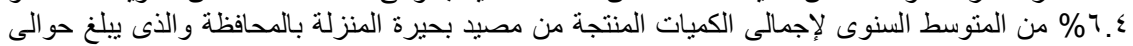

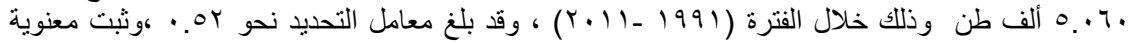

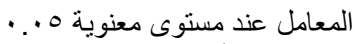

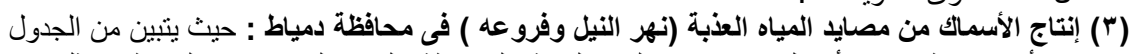

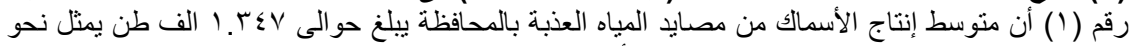

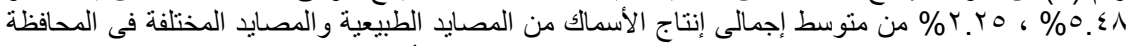

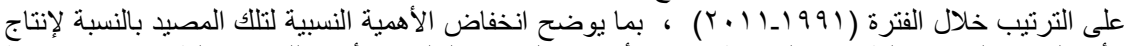

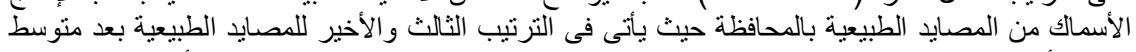

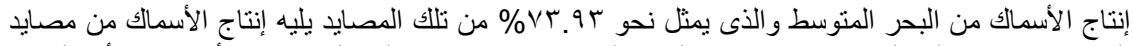

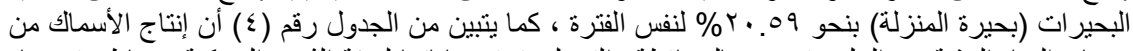

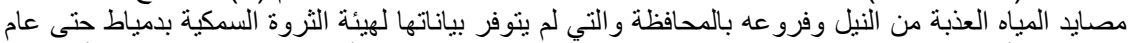

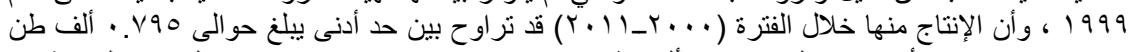

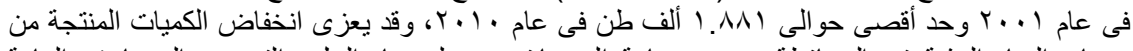

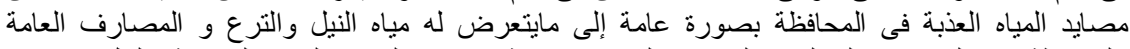

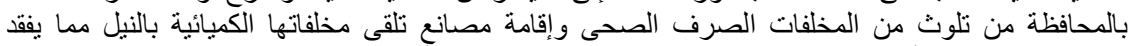

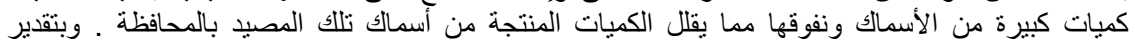

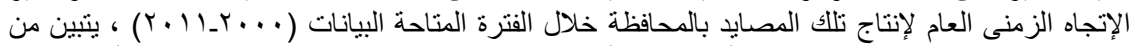

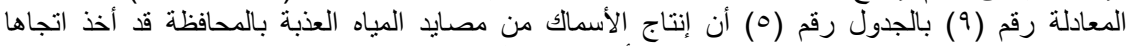

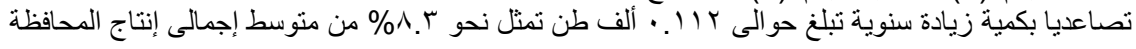


Hamida, S. A. M. and Y. T.A. Hamza

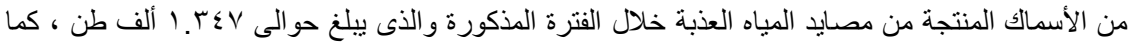

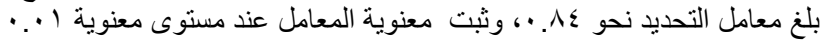

جدول رقم ( ؛ ) تطور إنتاج الأسماك من المصايد المختلفة فى محافظة دمياط خلال الفترة

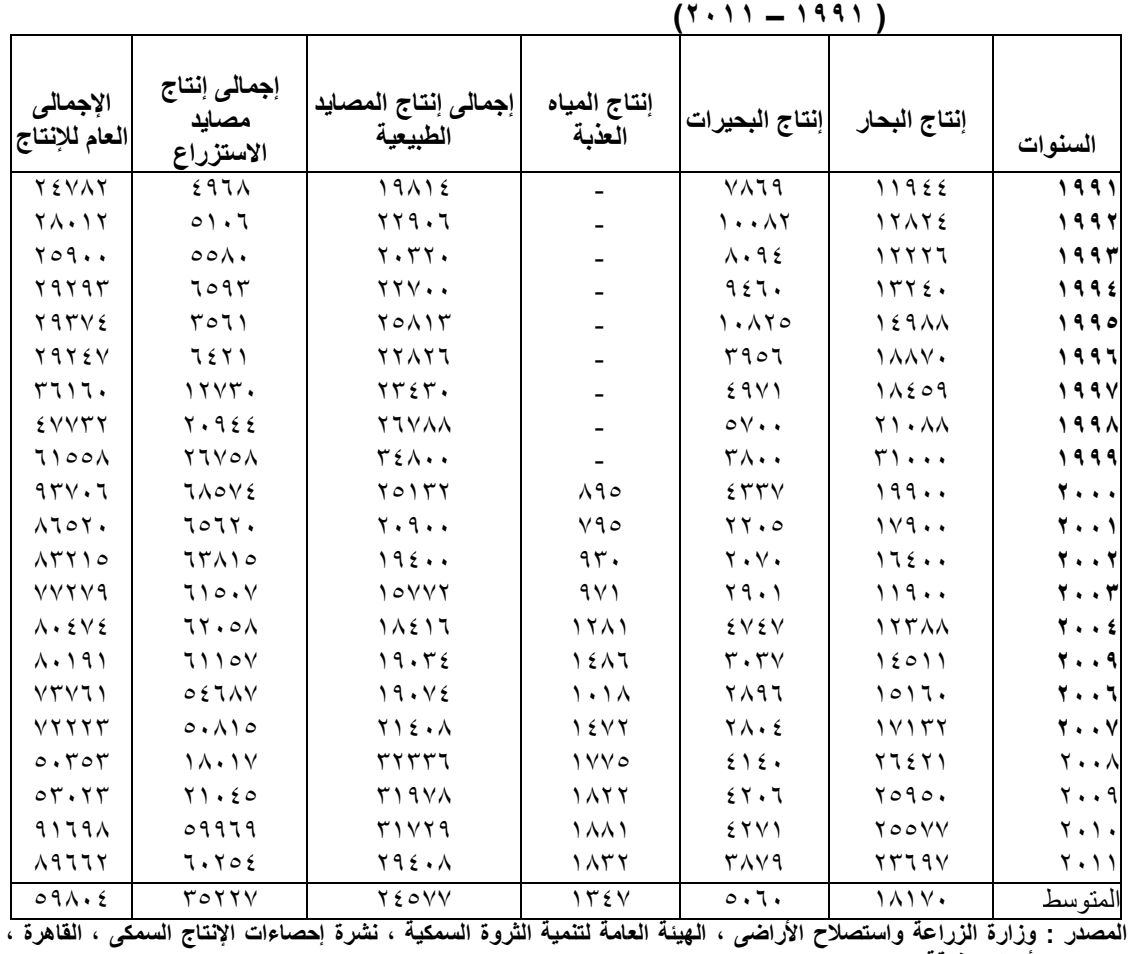
أعداد متفرقة.

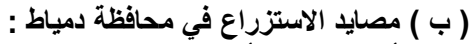

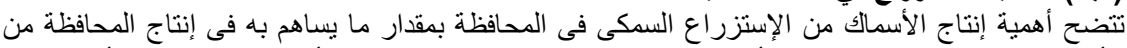

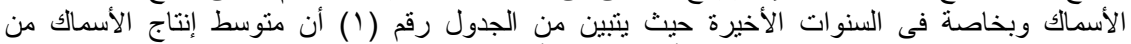

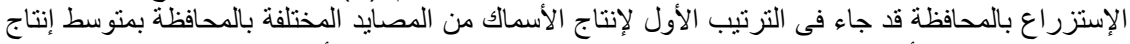

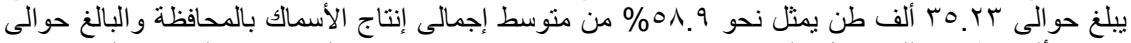

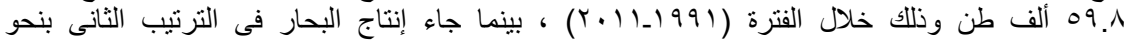

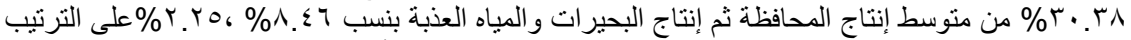

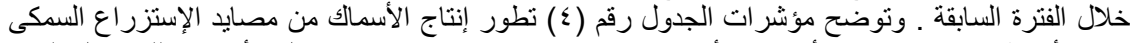

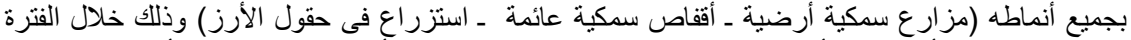

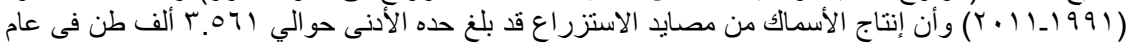

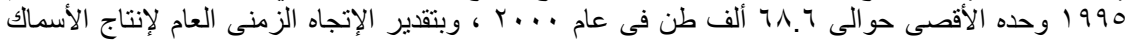

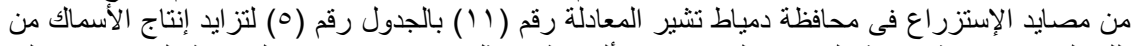

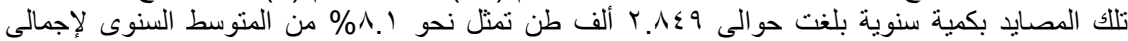

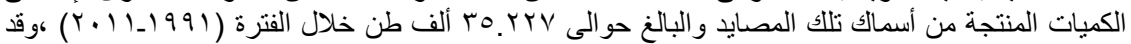

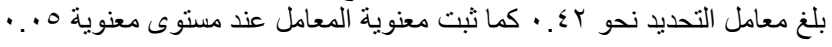


جدول رقم ( •) : معادلات الإتجاه الزمني العام لتطور إنتاج الأسماك من المصايد المختلفة فى محافظة

\begin{tabular}{|c|c|c|c|c|c|}
\hline المعنوية & ف & זر & 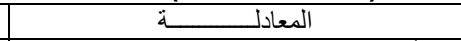 & رقم المعادلة & المصايد \\
\hline$\because .0$ & $\varepsilon . V T$ & $\cdot r \cdot \lambda$ & 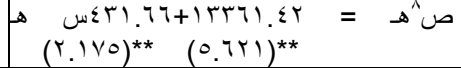 & $\left({ }^{V}\right)$ & إنتاج البحار \\
\hline$\because \cdot 1$ & 19.14 & .010 & 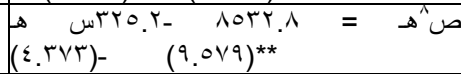 & $(\wedge)$ & إنتاج البحير ات \\
\hline$\because \cdot 1$ & $\leqslant 7.77$ &.$\wedge r \wedge$ & 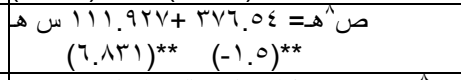 & (9) & إنتاج المياه العذبة \\
\hline - & $1.9 \leq 7$ & $\because .00$ & 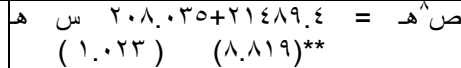 & $(1 \cdot)$ & الطبيعية المصيد \\
\hline$\because .0$ & $1 r .1 V$ & $\cdot . \leqslant Y Y$ & 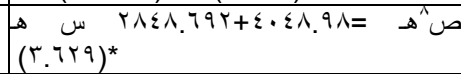 & $(11)$ & الاستزر اعايد \\
\hline$\because .1$ & $r \cdot .19$ & .049 & 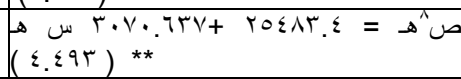 & $(I Y)$ & 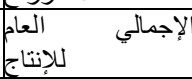 \\
\hline
\end{tabular}

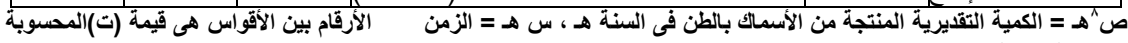

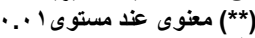

المصدر : جمعت وحسبت من البيانات الواردة بالجدول رقم (؛ ) مدري

يستخلص من العرض السابق للملامح الرئيسية لإنتاج الأسماك فى كل من الجمهورية ومحافظة

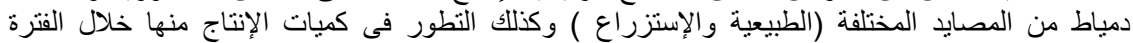

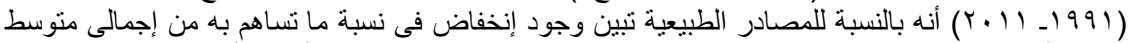

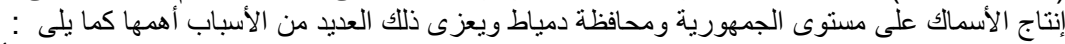

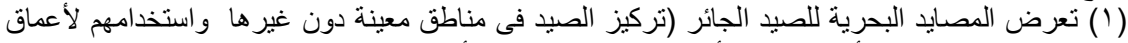

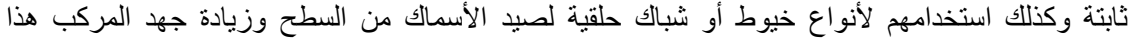

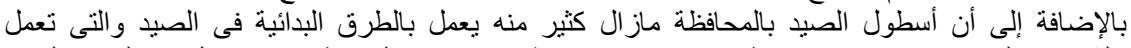

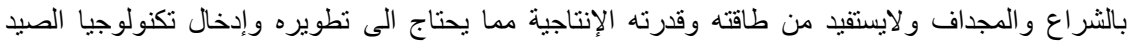

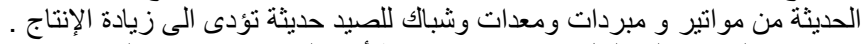

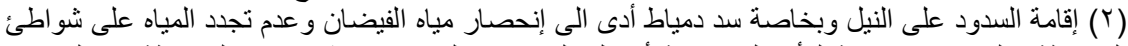

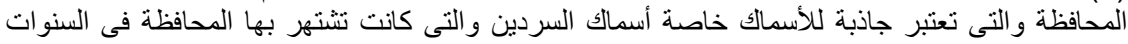

(r) مشاكل خاصة بالتلوث وبخاصة تلوث مياه النيل وبحيرة المنزلة و إلقاء المخلفات الملوثة من الإستخدام

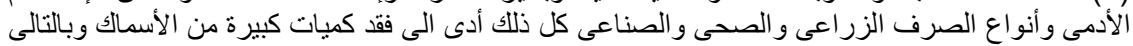

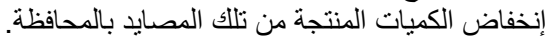

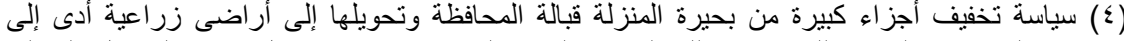

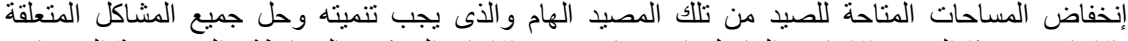

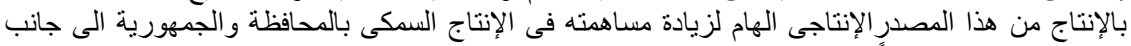

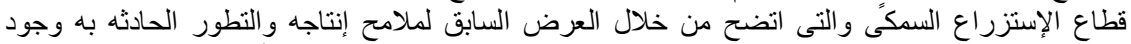

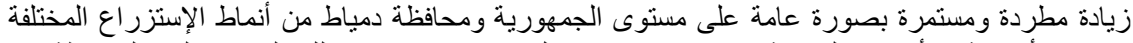

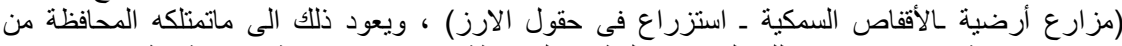

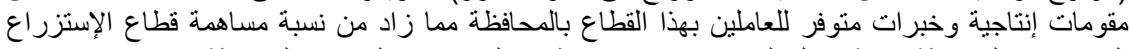

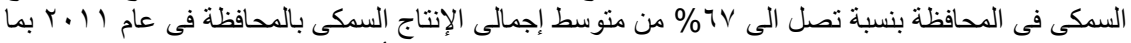
يتطلب معه حل كثير من المشاكل التى تواجه العاملين بقطاع إنتاج الأسماك من الإستزراع الإع السمكى بجميع

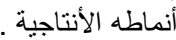

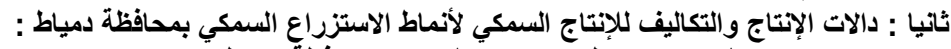

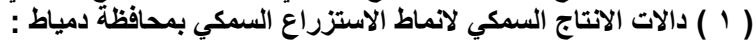

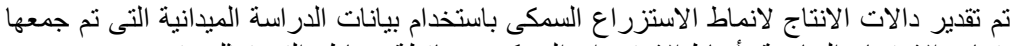

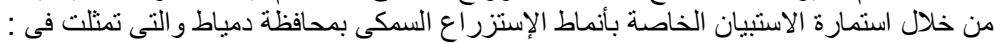

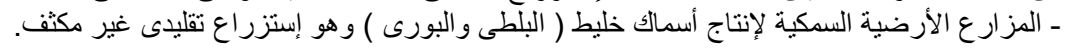


Hamida, S. A. M. and Y. T.A. Hamza

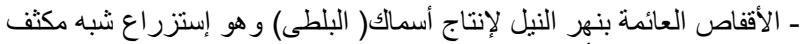

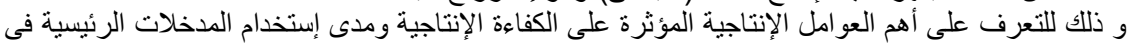

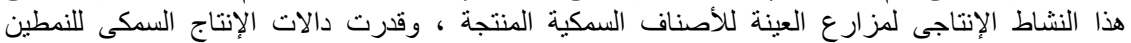

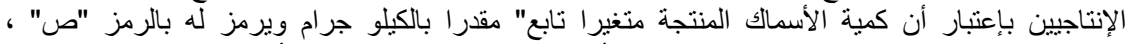

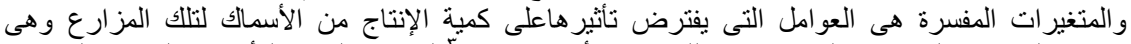

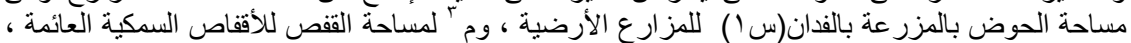

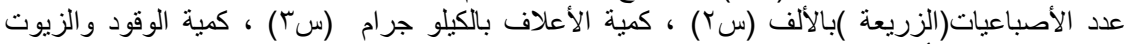

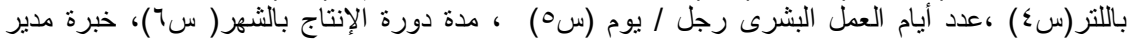

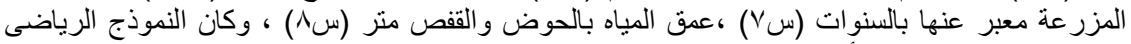

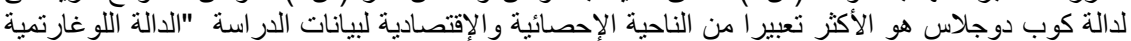

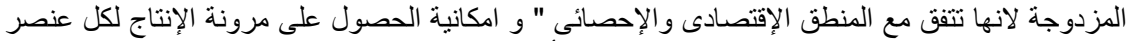

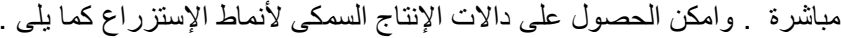

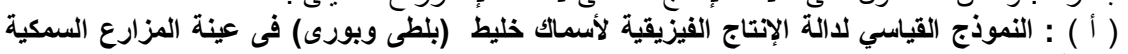
تشير بيانات المعادلة رقم ( باط ) الى دالة الإنتاج لأسماك الخليط ( بلطي وبوري ) في عينة

:بامياط : المز ار ع السمكية بمحافظة دمياط المعالة :

$(1 T)$

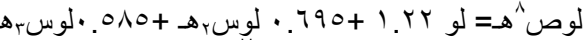
$\left(\leqslant .7 r_{0}\right)$ ** $(Y, V Y)$

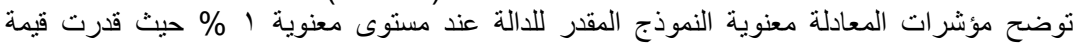

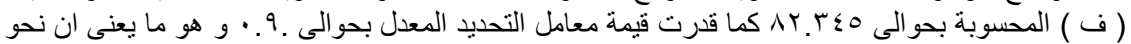

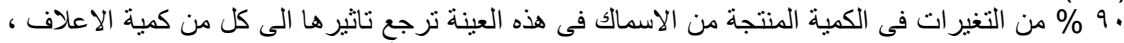

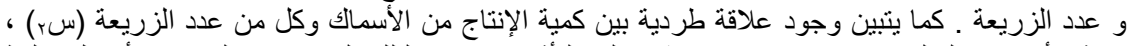

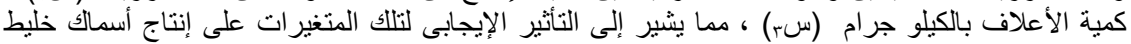

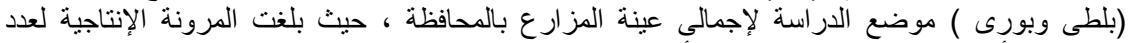

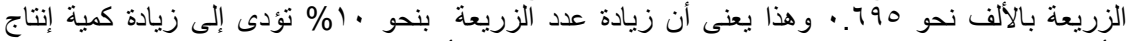

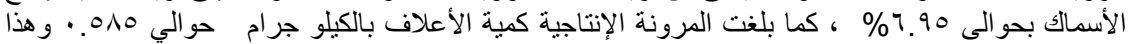

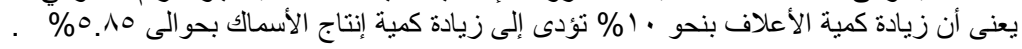

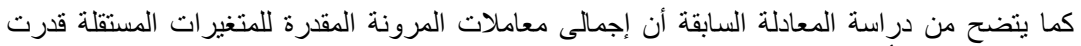

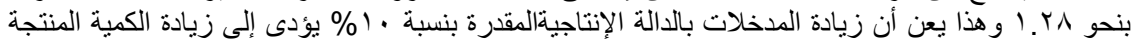

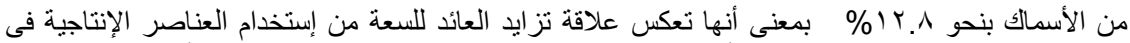

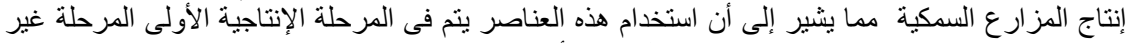

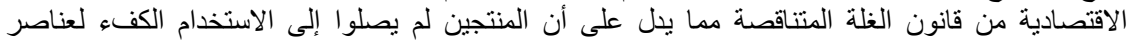

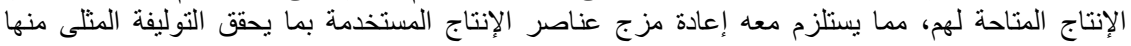

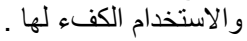

( بُ ): النموذج القياسي لالة الإنتاج الفيزيقية لأسماك البلطى فى عينة الأقفاص السمكية العائمة فى

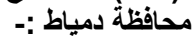
يتبين من المعادلة رقم ( ع أن ) أن دالة انتاج الأسماك البلطي في عينة الأقفاص السمكية العائمة بمحافظة دمياط

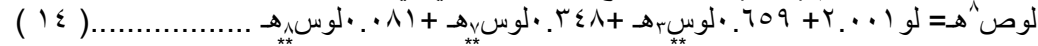

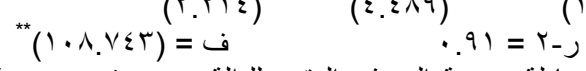

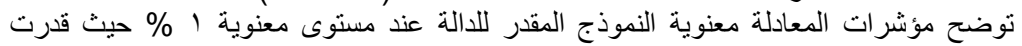

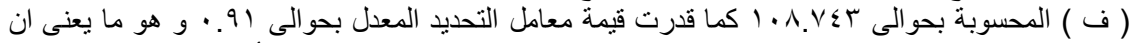

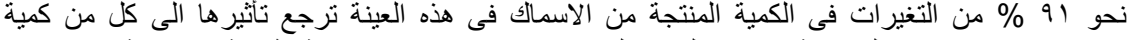

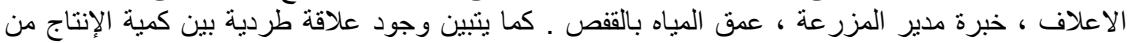

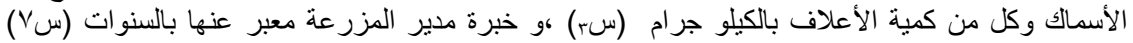




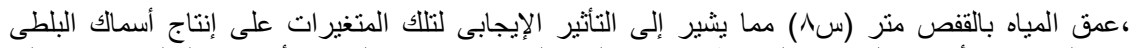

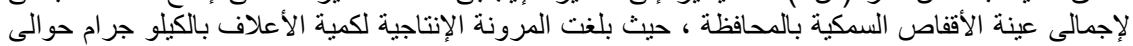

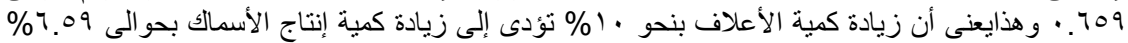

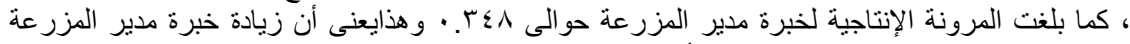

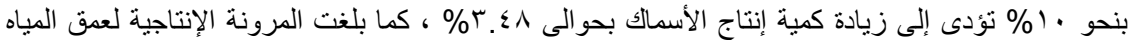

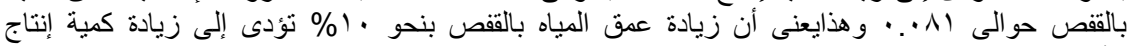

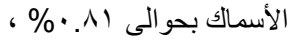

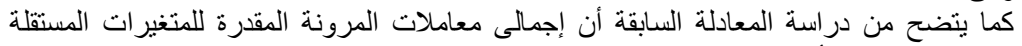

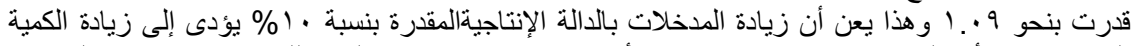

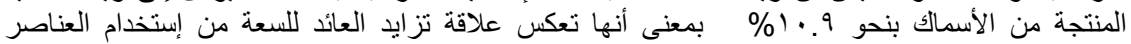

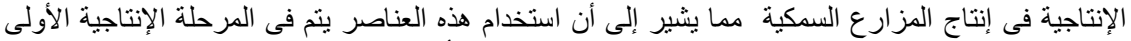

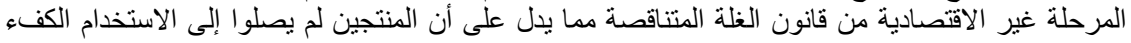

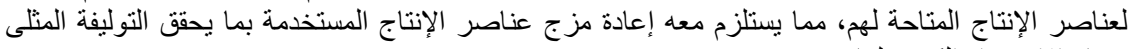

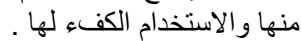

ثالثا : قياس بعض مؤشرات الكفاءة الانتاجية و الاقتصادية لأنماط الاستزراع السمكى بمنطقة الدراسة

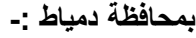

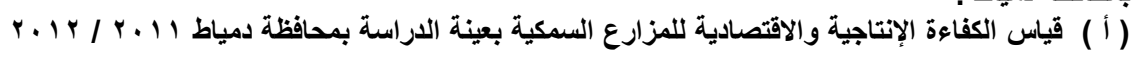

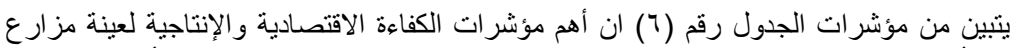

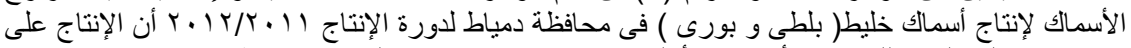

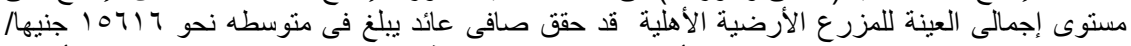

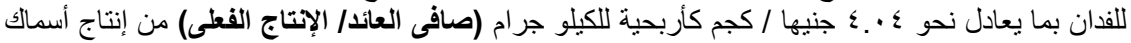

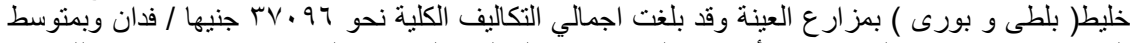

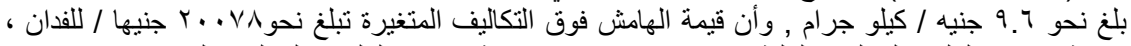

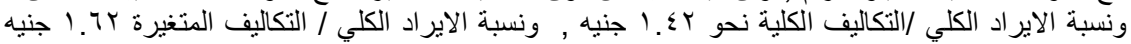

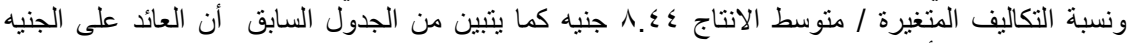

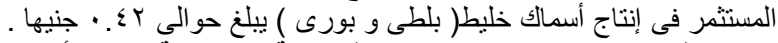

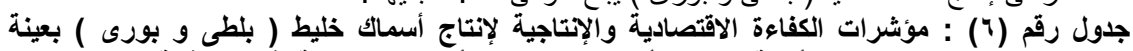

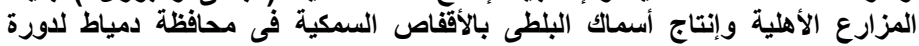

\begin{tabular}{|c|c|c|}
\hline إجمالي عينة الأقفاص السمكية & إجمالي عينة مزارع اسماك خليط & | - المؤشرات \\
\hline $11 \ldots$ & $\sum \leqslant 7 Y$ & التكاليف الثابتة ( جنيه ) \\
\hline $1 \cdot 1 \cdot \leq 4$ & TYTRS & التكاليف المتغيرة ( جنيه ) \\
\hline $1.91 \leqslant 7$ & $T V .97$ & التكاليف الكلية ( جنبه ) \\
\hline $1 \leq \leqslant .9$ & КАт० & متوسط الإنتاج ( كجم / فدان ) \\
\hline$Y .7$ & 9.7 & متوسط التكاليف الكلية \\
\hline $1 \leqslant 170$. & OYVIT & الاير اد الكلي ( جنيه ) \\
\hline$r 90 . \leqslant$ & 10717 & صافي العائد ( جنيه ) \\
\hline $1 . r 4$ & $1 . \leqslant Y$ & نسبة الإير اد الكلي / التكاليف الكلية \\
\hline $1 . r \Lambda$ & $1.7 \mathrm{~T}$ & نسبة الإير اد الكلي / التكاليف المتغيرة \\
\hline V.o & 1. $\varepsilon \varepsilon$ & نسبة التكاليف التتغيرة / متوسط الانتاج \\
\hline .47 & 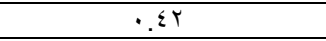 & أربحية الجنيه ( صافي العائد / ت ـ ك ) \\
\hline$\varepsilon \cdot 7 \cdot \varepsilon$ & $r \ldots v \wedge$ & الهامش فوق التكاليف المتغيرة ( جنيه ) \\
\hline Y.V & $\varepsilon . \cdot \varepsilon$ & الإنتاج الفعلي ) جنيل الكيلو ( صافي العائد / \\
\hline
\end{tabular}


Hamida, S. A. M. and Y. T.A. Hamza

( ) (ب ) باس الكفاءة الإنتاجية والاقتصادية للأقفاص السمكية بعينة الاراسة بمحافظة دمياط موسم

$(r+1 r / r+11)$

يتبين من مؤشرات الجدول رقم ( 1 ( ) ان أهم مؤشرات الكفاءة الاقتصادية والإنتاجية لعينة

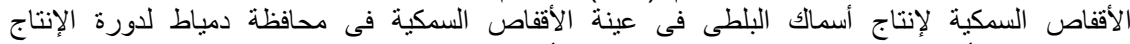

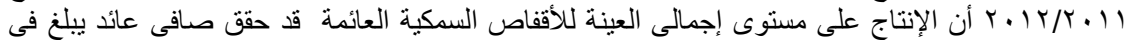

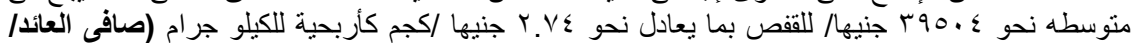

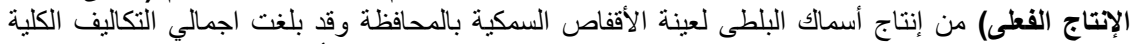

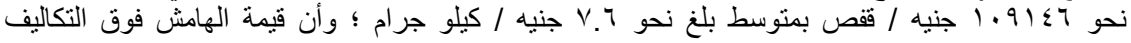

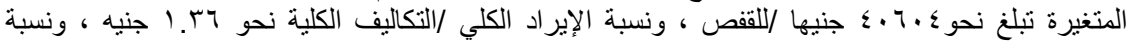

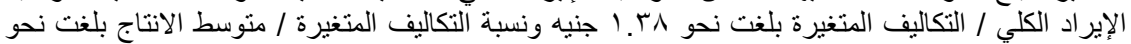

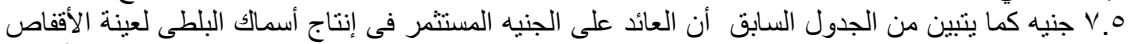

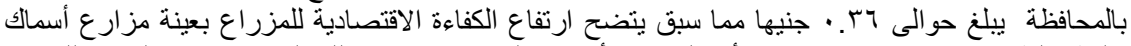

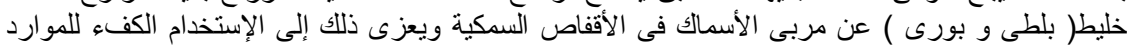

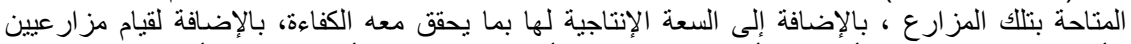

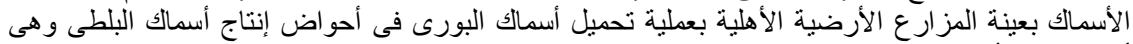

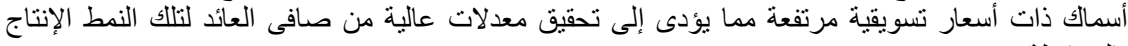

بالمحافظة.

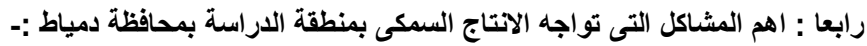

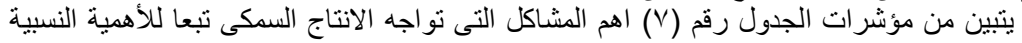

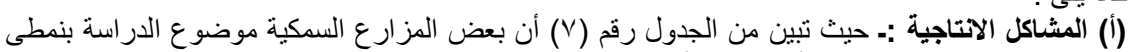

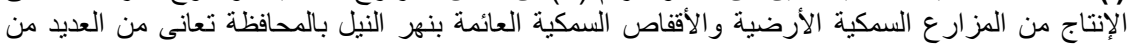

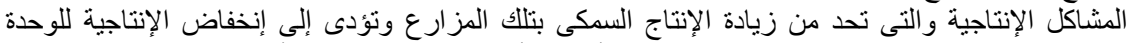

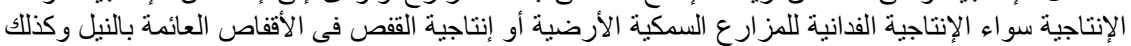

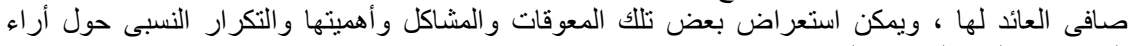

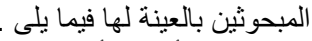

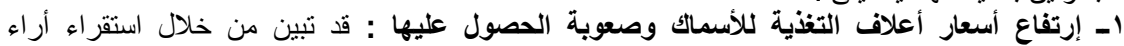

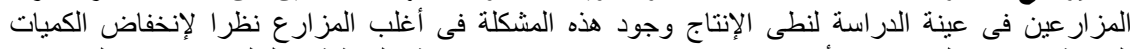

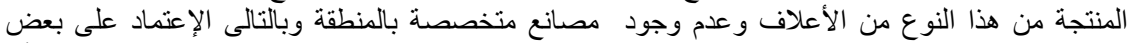

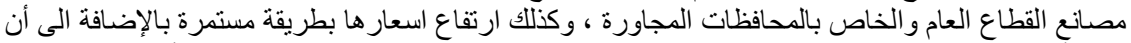

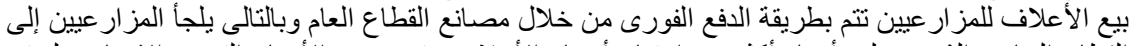

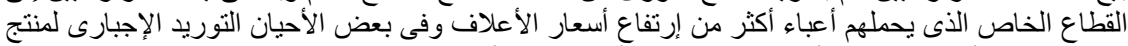

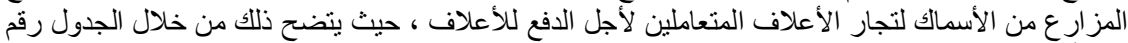

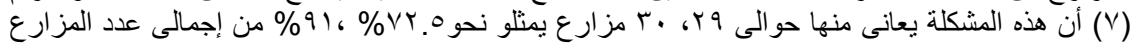

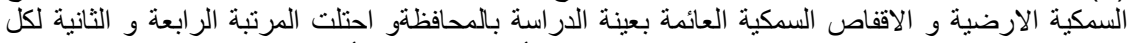

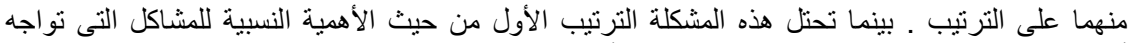

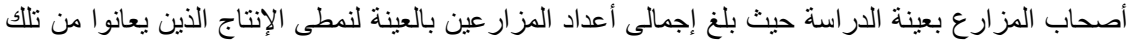

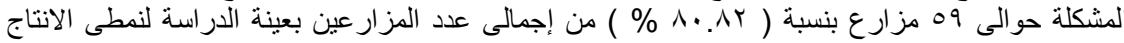

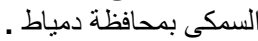

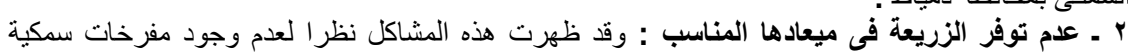

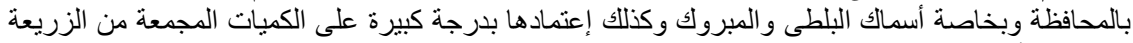

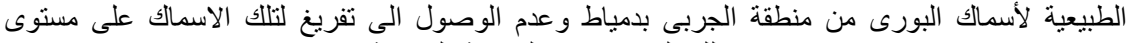

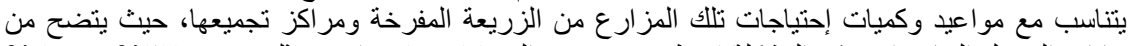

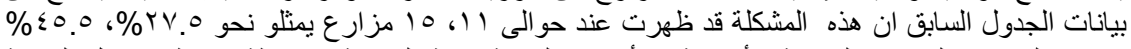

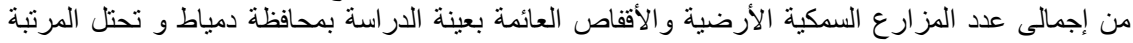

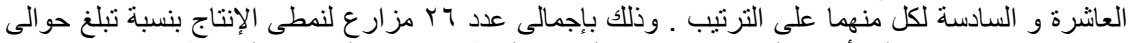

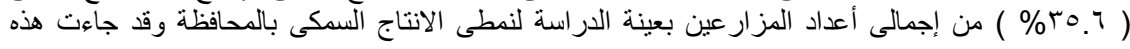


المشكلة فى الترتيب العانشر والأخير تبعا للترتيب التنازلى للأهمية النسبية لمشاكل المزارعين بعينة المزارع

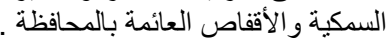
r - إرتفاع أسعار الزريعة وزيادة نسبة النفوق الثبائة أثناء عملية النقل : وقد ظهرت مشكلة إرتفاع أسعار الزريعة

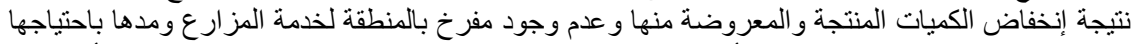

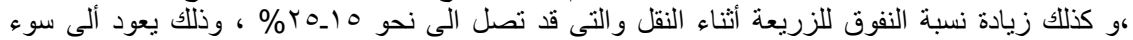

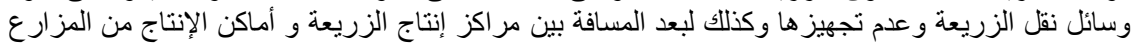

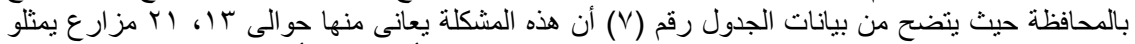

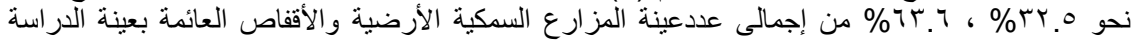

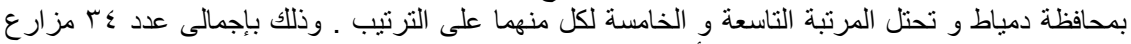

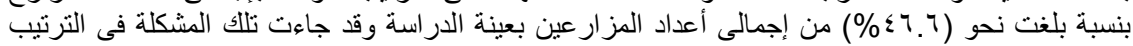

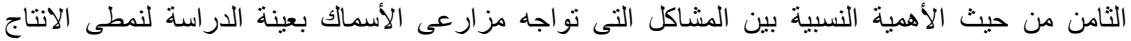

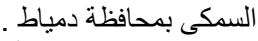

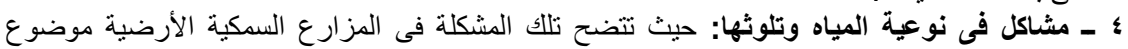

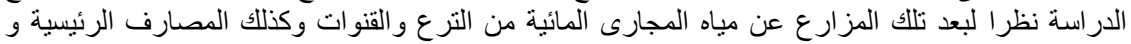

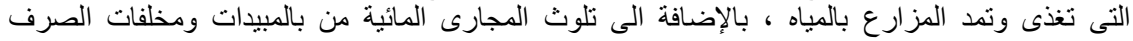

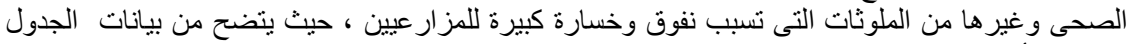

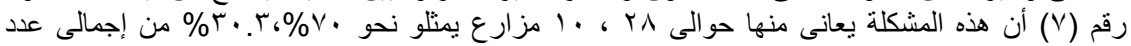

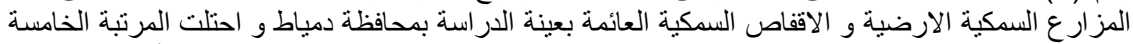

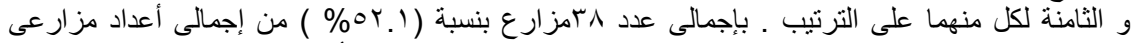

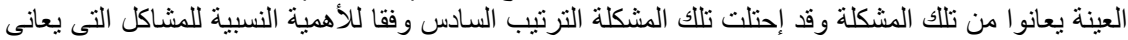

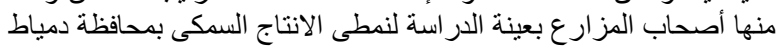

جدول رقم ( V ) الأهمية النسبية لأراء أصحاب المزارع السمكية حول المشكلات التى تواجههم بمنطقة

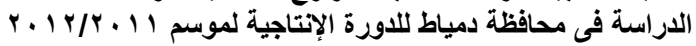

\begin{tabular}{|c|c|c|c|c|c|c|c|c|c|}
\hline \multirow[b]{2}{*}{ التلأهمية تبعا } & \multirow[b]{2}{*}{\begin{tabular}{|c|} 
م العنمالي \\
\\
\end{tabular}} & \multirow{2}{*}{ الجمالى } & \multicolumn{3}{|c|}{ الأقفاص السمكية } & \multicolumn{3}{|c|}{ المزارع الأرضية } & \multirow[b]{2}{*}{ المشاكل } \\
\hline & & & الترتيب| & 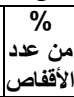 & عدد & | الترتيب & \begin{tabular}{|c|} 
\\
\\
\\
\\
\end{tabular} & $q$ & \\
\hline & & & & & & & & & | (أ) المشاكل الانتاجية \\
\hline (') & A. .Ar & 09 & $(r)$ & 9) & r. & $(\varepsilon)$ & VY.O & rq & الحصول إرتفاع أسعار أعلاف التخذية للأسماك وصعوبة \\
\hline (1.) & ro. 7 & ז & (ヶ) & $\leqslant 0.0$ & 10 & $(1 \cdot)$ & $r V . O$ & 11 & r ـ عدم توفر الزريعة في ميعادها المناسب \\
\hline$(\wedge)$ & $\leqslant 7.7$ & $r \varepsilon$ & (०) & T. & r) & (9) & rr.o & $1 \pi$ & r-r- إرتفاع أسعار الزريعة وزيادة نسبة النفوق أثناء \\
\hline (?) & or.1 & rᄉ & $(\wedge)$ & $r \cdot r$ & 1. & $(0)$ & v. & $r \wedge$ & | \\
\hline$(\vee)$ & $\leq 9 . \%$ & דיץ & - & - & - & ( $)$ & 9. & $r 4$ & | \\
\hline$(\varepsilon)$ & 70.1 & «^ & $(\Gamma)$ & $\wedge 1 . \wedge$ & Tr & $(\wedge)$ & or.o & r) & 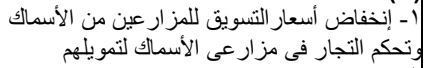 \\
\hline (9) & $\varepsilon 0, Y$ & זיז & - & - & - & $(r)$ & Ar.o & זr & 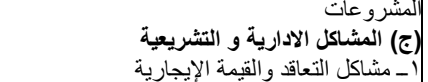 \\
\hline$(r)$ & vo.r & $\infty 0$ & ( $)$ & 97.9 & rt & $\left(v^{\prime}\right)$ & ov.o & rt & 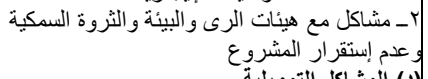 \\
\hline (0) & $0 \leqslant . \wedge$ & $\varepsilon$. & $(\mathrm{v})$ & ra. & ir & $(7)$ & TV.o & $r v$ & |- - عجز التمويل والخدمات التمويلية للمزارع ـ . \\
\hline
\end{tabular}


Hamida, S. A. M. and Y. T.A. Hamza

\begin{tabular}{|c|c|c|c|c|c|c|c|c|c|}
\hline$(r)$ & $V \varepsilon$ & $0 \leqslant$ & $(\varepsilon)$ & 79.1 & rT & $(r)$ & $V Y . O$ & $r$ & 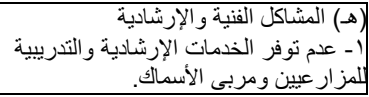 \\
\hline
\end{tabular}

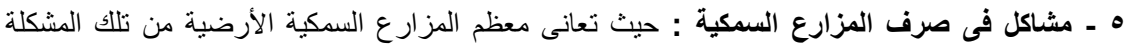

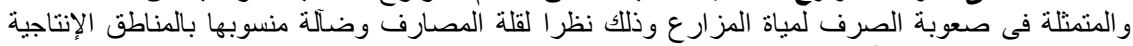

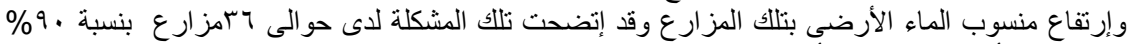

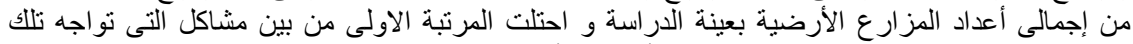

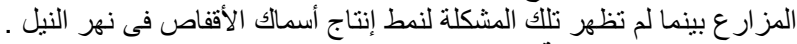

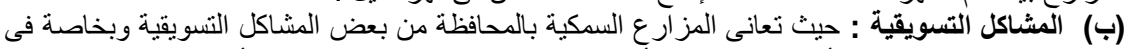

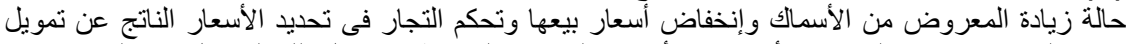

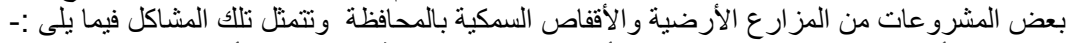

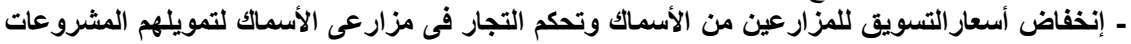

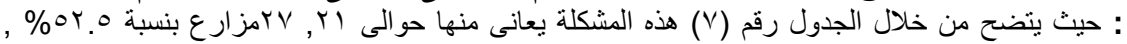

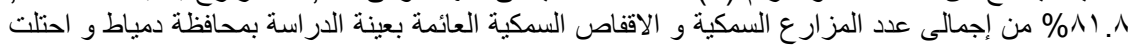

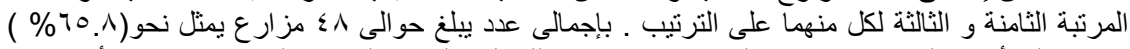

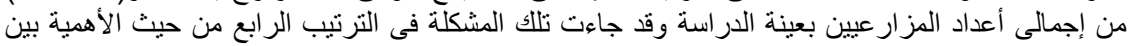

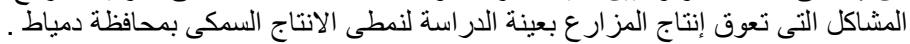

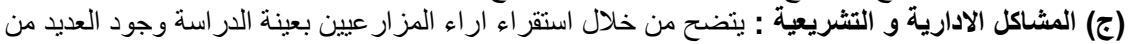

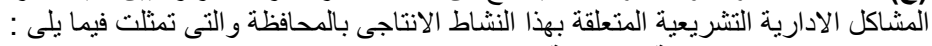

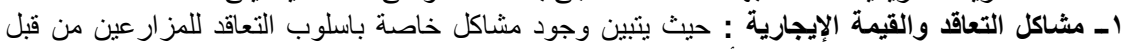

هيئة الثروة السمكية بالمنطقة وكذلك الأسلوب الايجارى من الباطن و التى تنز ايد فيه القيمة الإيجارية للفدان

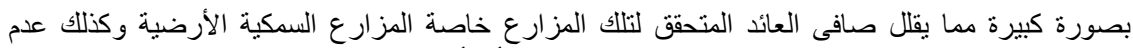

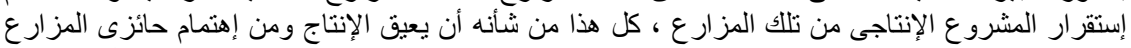

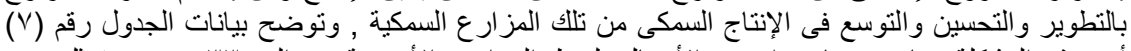

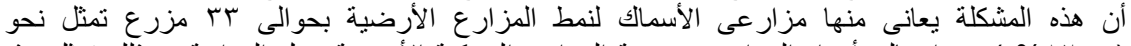

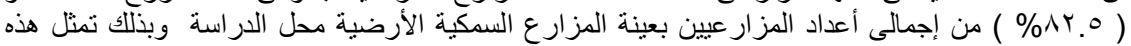

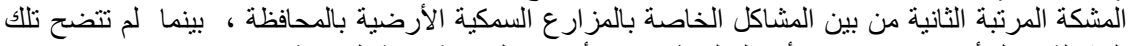

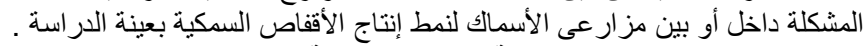

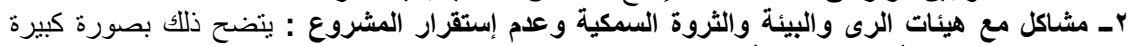

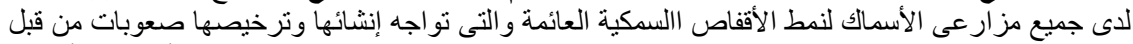

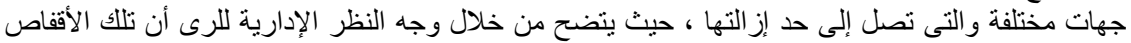

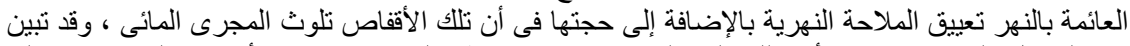

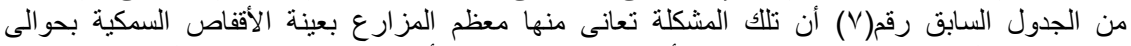

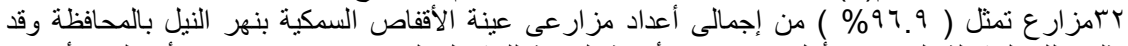

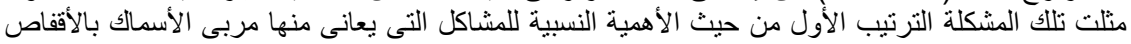

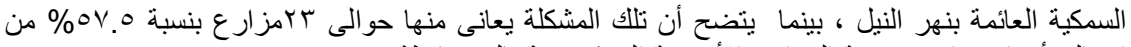

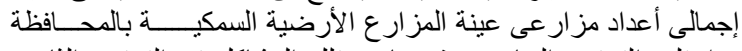

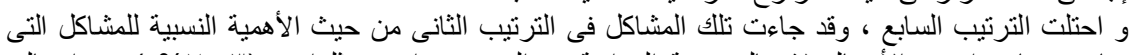

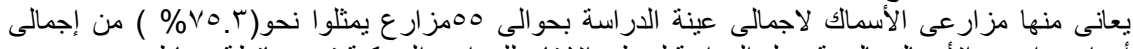

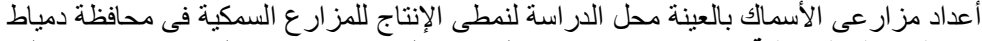

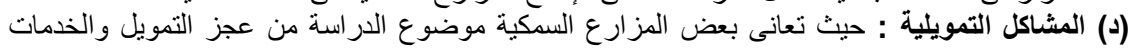

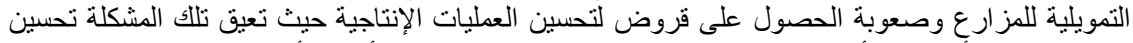

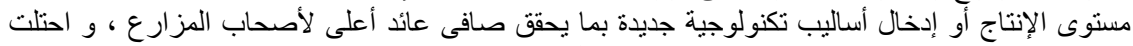

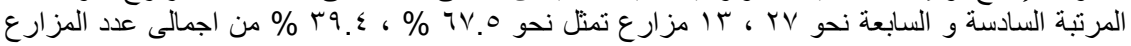

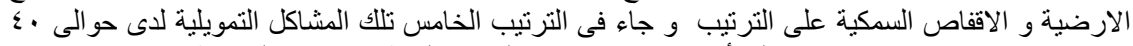
مز ارع بنسبة ( ^. ؛०\% ) من إجمالى أعداد مز ارعى عينة الدراسة لنمطى الانتاج بالمحافظة . 
(هـ) المشاكل الفنية والإرشادية : و التى ثتمثل فى عدم توفر الخدمات الإرشادية والتدريبية لمزارعى الأسماك

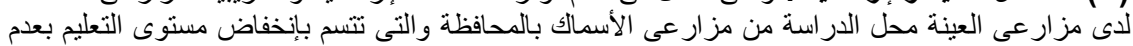

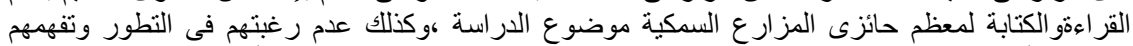

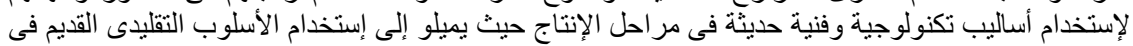

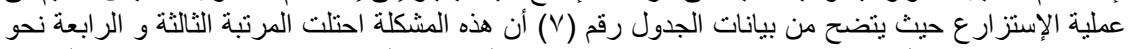

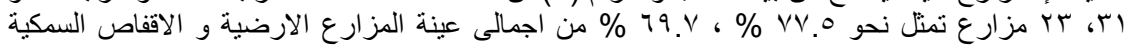

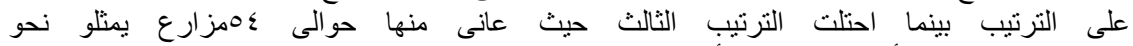

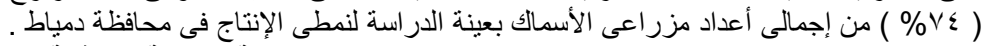

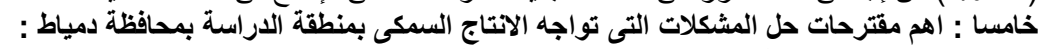

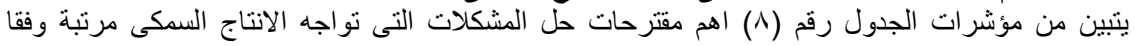

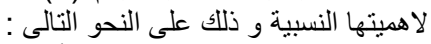

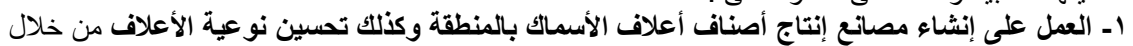

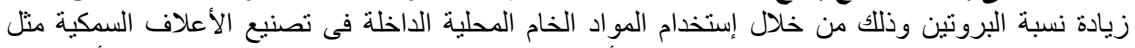

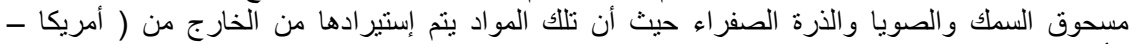

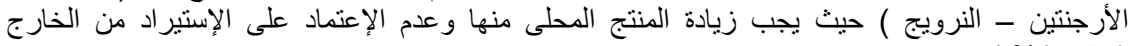

. (\%9. ( )

r - توفير جهاز ارشادى لتوجيه وتدريب مزارعى الأسماك من قبل الهيئة العامة للثروة السمكية لتقديم

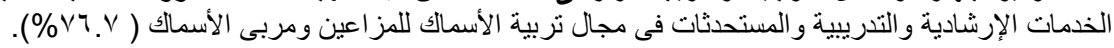

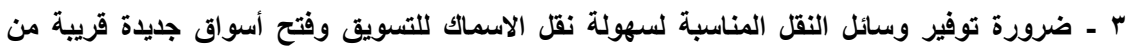

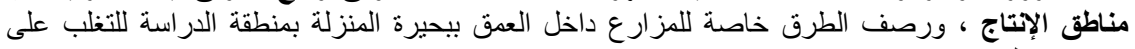

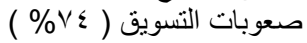

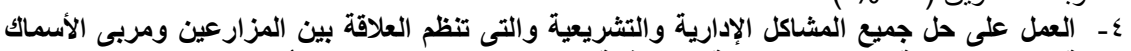

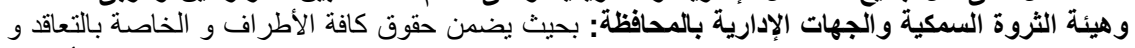

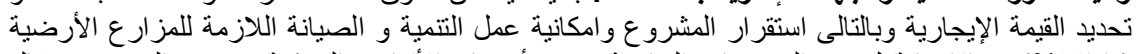

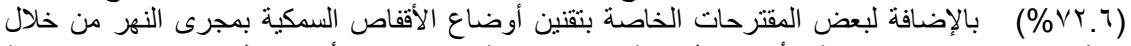

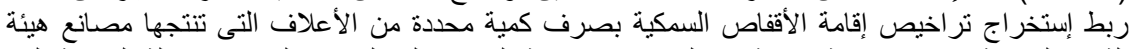

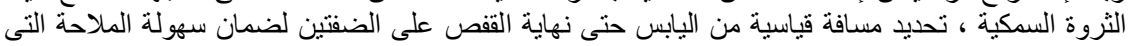

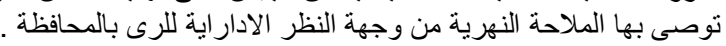

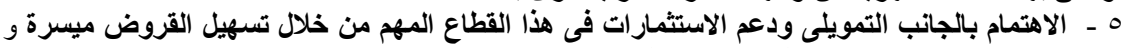

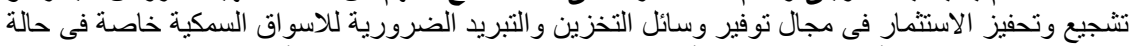

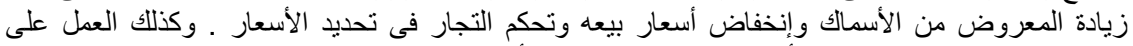

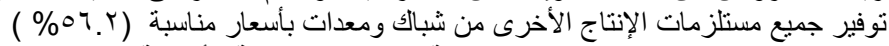

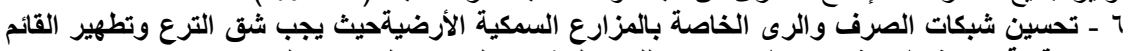

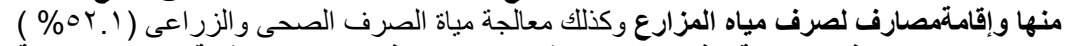

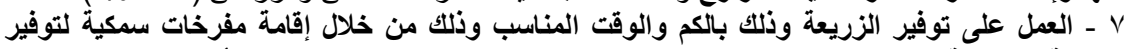

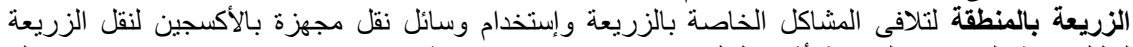

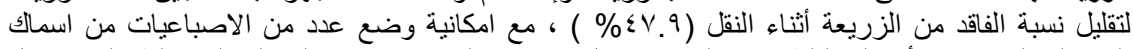

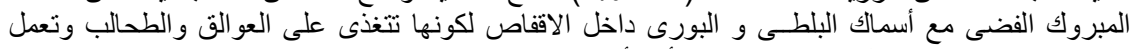

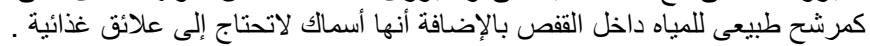
توصيات الاراسة :

العمل على إنشاء مصانع أعلاف الأسماك بالمنطقة وتحسين نوعيتها علاوة على توفير جهاز

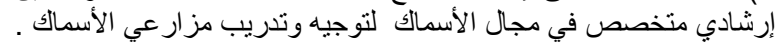


Hamida, S. A. M. and Y. T.A. Hamza

جدول رقم ( ^) الأهمية النسبية والتكرارات لمقترحات مزارعى الأسماك للتظلب على المشاكل التى تواجهم

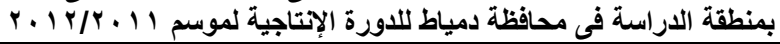

\begin{tabular}{|c|c|c|}
\hline$\%$ & العدد & الحلول والمقترحات \\
\hline $9 \cdot . \varepsilon$ & 77 & ا ـ العمل على إنشاء مصانع إنتاج أصناف أعلاف الأسماك بالمنطقة وكذلك تحسين نوعية الأعلاف. \\
\hline$\vee\urcorner . V$ & 07 & r- توفير جهاز ارشادى لتوجيه وتدريب مزارعى الأسماك. \\
\hline$V \leq \ldots$ & $0 \leqslant$ & ץ- - ضرورة نوفير وسائل النقل المناسبة لسهولة نقل الاسماك للتسويق وفتح أسواق جديدة قريبة من مناطق \\
\hline VY.T & or & و ــ العملة الثرة السمى حلة جميع المشاكل الإدارية بالمارية والقظة. \\
\hline $07 . \mathrm{Y}$ & $\varepsilon 1$ & هـ الاهتمام بالجانب التمويلى ودعم الإستثمار ات فى هذا القطاع المهم من خلال تسهيل قروض ميسرة. \\
\hline Or. 1 & & من - تحسين و اقامة مصاكات الصرف لصرف والرى الخاص الخة بالمز ارع السمكية الأرضيةحيث يجب شق الترع وتطهير القائح \\
\hline$\leqslant \vee .9$ & ro & الزريعة بالمنطقة على العير الزريعة وذلك بالكم والوقت المناسب وذلك من خلال إقامة مفرخات سمكية لتوفير \\
\hline
\end{tabular}

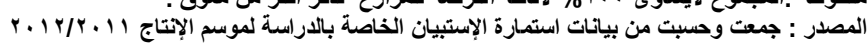

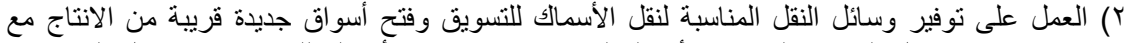

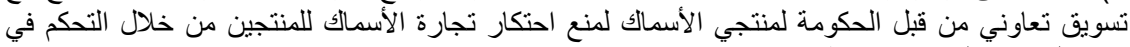

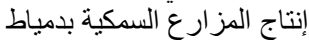
r) العمل على توفير الزريعة وذلكية اللك بالكم والوقت المناسب وذللك من خلال اقامة مفرخات سمكية لتوفير

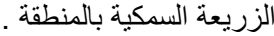

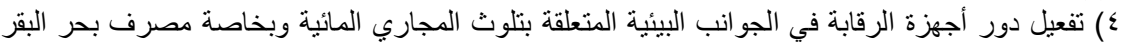

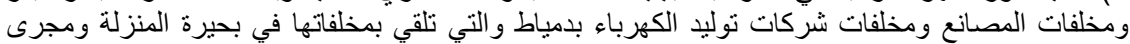

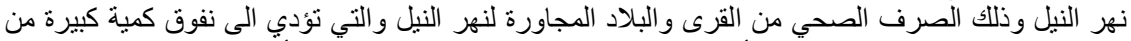

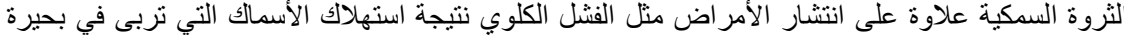

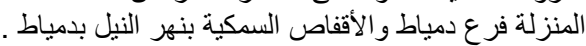

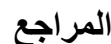

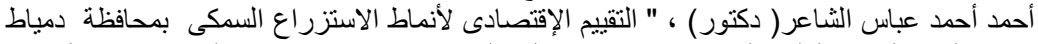

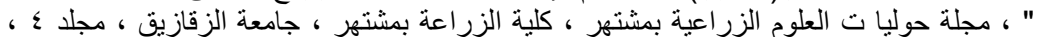

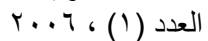

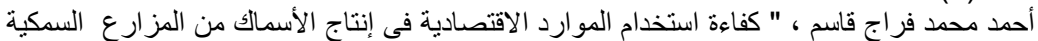

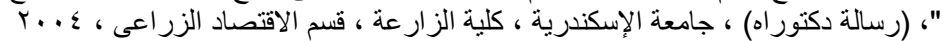

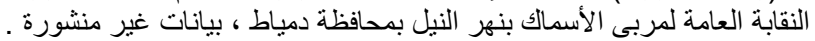

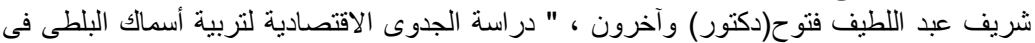

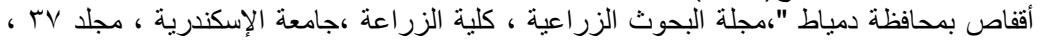

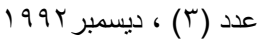
محافظة دمياط ،مركز المعلومات ودعم اتخاذ القرار،نشرة وصف محافظة دمياط بالمعلومات أعداد متفرقة

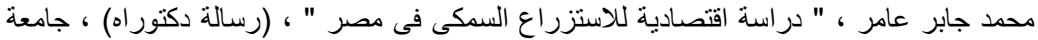

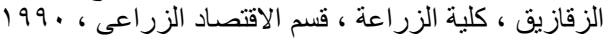

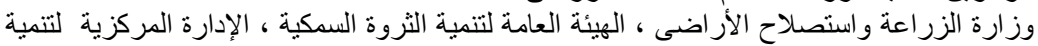

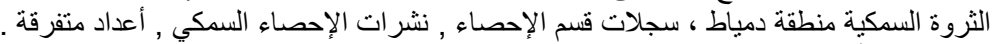

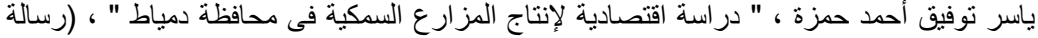

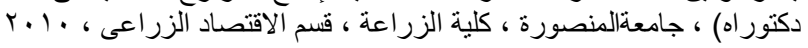




\section{ECONOMIC STUDY FOR FISH PRODUCTION IN DAMIETTA GOVERNORATE}

Hamida, S. A. M. and Y. T.A. Hamza

Agric. Economic Res. institute. Agric. Res. Center

To Find a Future Vision for Fish Production in Damietta Governorate to increase Fish production consequently enlarging this important Productive activity in The governorate. Also, it provides a Permenant and Continuous Source of Fish Production achieving a Propertional Stability in Fish Prices especially the economic Fish of local demand From Tilapia, Mullet and El tobar.

The Study Showed that the average of production in The Governorate From The Natural Fisheries reaches about 24,6 Thousand Tons which represents $41,09 \%$ from The average of The Total Fish Production From The different Fisheries in The Governorate and about 6,7 $\%$ From The average of The Total Fish production From The natural Fisheries in The republic which is about 367, 2 Thousand tons during The Period ( 1991 - 2011).

The Time general attitude refers to an annual decrease Which is about $0,432-0,325-0,208$ in Damietta during ( $1991-2011)$ From Sea lakes and clear water. This amount represents $2,4 \% 6,4 \%-15,4 \%$ From The annual average Of The Total amount produced From Fish in The governorate respectively during the mentioned Period.

The study also Showed That The average of Fish Production From the aquaculture in the republic during $(1991-2011)$ reached about 375,9 Thousand tons which represents about $50,59 \%$ From The total average of Fish production From the different Fisheries which reached about 743,05 Thousand tons as an average of the same Period.

Also . the average of the aquaculture in the governorate about 35,23 thousand tons which represents $9,4 \%$ From the total aquaculture in the republic . it contributed with about $58,9 \%$ From the total average of Fish Production in Damietta..

Which reaches about 59, 8 thousand tons during The Same Period . it also Shows That the average of First Production From Fish farms represents The Fist rank For fish Production of different aquaculture types in the governorate.

It's shown from the results of the economic analysis for the functions of fish Production of mixed fish ( tilapia and mullet ) in the sample of fish farms that there is a positive relationship between the amount fish production and the number of small fish and the amount of fodder with kilogram. This indicates that there is a positive influence for these variables on fish production of ( tilapia and mullet) . the total of elasticity factors are estimated with 1.28 , also it is shown from the results of the economic analysis for the functions of fish production for tilapia from the fish cages in the governorate that there is a positive relationship between the amount of fish production and all the amount of fodder with kilogram and the experience of the farm manager expressed in number of years, and the depth of water in 
the cage in meter this indicates that there is a positive influence of these variable on the fish production of tilapia in the governorate . the total of Elasticity factors are estimated with 1.09

It's shown from the indicators of productive and economic efficiency for the sample of the study that the land fish farms reached an average for the total costs for the feddan about 37096 pounds / feddan and the net profit is about 156616 pounds / feddan and the a profit per invested pound 0.42 concerning the fish cages the total costs reached an average about 109146 pounds / cage and the net return is about 39504 and the a profit per invested pound 0.36

The study showed also that the most important production , markting administrative and legislative problems facing aquaculture activity in the sample's study in Damietta Governorate according to its relative importances were : the deficit of fodders and its high prices and the unstability of the project with : $79.2,81.9$ and $76.4 \%$ consequently from the total units of the sample size .

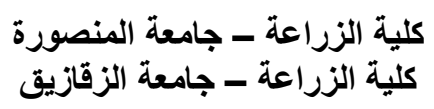

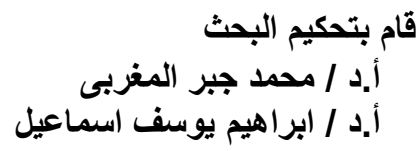

